\title{
Cellular toxicity of dietary trans fatty acids and its correlation with
}

\section{ceramide and diglyceride accumulation}

Farkas Sarnyai ${ }^{1}$, Mária Berinkeiné Donkó ${ }^{2}$, Judit Mátyási ${ }^{3}$, Zsófia Gór-Nagy ${ }^{2}$, Ildikó Marczi ${ }^{1}$, Laura Simon-Szabó ${ }^{4}$, Veronika Zámbó ${ }^{1}$, Anna Somogyi ${ }^{1}$, Tamás Csizmadia ${ }^{5}$, Péter Lőw ${ }^{5}$, Péter Szelényi ${ }^{1}$, Éva Kereszturi ${ }^{1}$, Blanka Tóth $^{2 *}$, Miklós Csala $^{1 *}$

${ }^{1}$ Semmelweis University, Department of Medical Chemistry, Molecular Biology and Pathobiochemistry, Budapest, Hungary

${ }^{2}$ Budapest University of Technology and Economics, Department of Inorganic and Analytical Chemistry, Budapest, Hungary

${ }^{3}$ B\&B Analytics Ltd., Érd, Hungary

${ }^{4}$ Pathobiochemistry Research Group, Hungarian Academy of Sciences, Semmelweis University (MTA-SE), Budapest, Hungary

${ }^{5}$ Eötvös Loránd University, Department of Anatomy, Cell and Developmental Biology, Budapest, Hungary

*Corresponding authors:

Miklós Csala M.D., Ph.D., D.Sc.; Semmelweis University, Dept. of Medical Chemistry, Molecular Biology and Pathobiochemistry, H-1428, Budapest, POB: 2, Hungary; Email: csala@eok.sote.hu; Tel: + 3612662615

Blanka Tóth Ph.D.; Budapest University of Technology and Economics, Dept. of Inorganic and Analytical Chemistry, H-1111, Budapest, Szt. Gellért tér 4., Hungary; Email: tblanka@mail.bme.hu; Tel: + 3614631415

(C) 2018. This manuscript version is made available under the CC-BY-NC-ND 4.0 license http://creativecommons.org/licenses/by-nc-nd/4.0/

Short title: Effect of TFAs on ceramide and diglyceride levels in RINm5F cells Declarations of interest: none. 
Abbreviations: ASK1, apoptosis signal-regulating kinase 1; BAX, Bcl-2-assosiated X protein; CHOP, C/EBP homologous protein; eIF2 $\alpha$, eukaryotic initiation factor $2 \alpha$; ER, endoplasmic reticulum; DG, diglyceride; FFA, free fatty acids; GAPDH, glyceraldehyde 3-phosphate dehydrogenase; GC-FID, gas chromatography-flame ionization detector; HPLC-MS/MS, high performance liquid chromatography-tandem mass spectrometry; IRE1, inositol-requiring enzyme 1; IRS, insulin receptor substrate; JNK, c-Jun-N-terminal kinase; LDH, lactate dehydrogenase; $\mathrm{NAD}^{+}$, nicotinamide adenine dinucleotide (oxidized); $\mathrm{NADH}$, nicotinamide adenine dinucleotide (reduced); NAFLD, non-alcoholic fatty liver disease; PERK, PKR-like ER kinase; UPR, unfolded protein response; TG, triglyceride; TFA, trans fatty acid; XBP-1, X box-binding protein-1.

\section{Highlights}

- Cellular metabolism and toxicity of TFAs are still to be elucidated.

- TFAs were incorporated in RINm5F insulinoma cells like palmitate or oleate.

- Similarly to oleate and unlike palmitate, TFAs were of mild toxicity.

- FA-induced cell damage correlated with ceramide and diglyceride accumulation.

- Incorporation of TFAs in ceramides and diglycerides exceeded that of oleate. 


\begin{abstract}
High fatty acid (FA) levels are deleterious to pancreatic $\beta$-cells, largely due to the accumulation of biosynthetic lipid intermediates, such as ceramides and diglycerides, which induce ER stress and apoptosis. Toxicity of palmitate (16:0) and oleate $\left(18: 1\right.$ cis- $\left.\Delta^{9}\right)$ has been widely investigated, while very little data is available on the cell damages caused by elaidate (18:1 trans- $\left.\Delta^{9}\right)$ and vaccenate $\left(18: 1\right.$ trans- $\left.\Delta^{11}\right)$, although the potential health effects of these dietary trans fatty acids (TFAs) received great publicity. We compared the effects of these four FAs on cell viability, apoptosis, ER stress, JNK phosphorylation and autophagy as well as on ceramide and diglyceride contents in RINm5F insulinoma cells. Similarly to oleate and unlike palmitate, TFAs reduced cell viability only at higher concentration, and they had mild effects on ER stress, apoptosis and autophagy. Palmitate increased ceramide and diglyceride levels far more than any of the unsaturated fatty acids; however, incorporation of TFAs in ceramides and diglycerides was strikingly more pronounced than that of oleate. This indicates a correlation between the accumulation of lipid intermediates and the severity of cell damage. Our findings reveal important metabolic characteristics of TFAs that might underlie a long term toxicity and hence deserve further investigation.
\end{abstract}

Keywords: ceramide; diglyceride; apoptosis; endoplasmic reticulum stress; diabetes; trans fatty acids 


\section{Introduction}

Free fatty acids (FFA) are produced in the adipocytes by the hydrolysis of storage triglycerides in starvation, and they are associated to albumin in the blood plasma. Once entering the cytosol, they are conjugated with Coenzyme A, forming fatty acyl-CoA, a central intermediate in lipid metabolism, which can be inserted in complex lipids, such as di- and triglycerides (DGs and TGs), phosphoglycerolipids, ceramides and other sphingolipids or cholesterylesters [1].

Excessive supply of FFA in obesity is deleterious to many cell types [2]. Since FFA surplus both induces insulin resistance and reduces the capacity of pancreatic $\beta$-cells to secrete insulin, lipotoxicity is widely regarded as a key link between overweight and type 2 diabetes [3]. The complex intracellular mechanism of lipotoxicity has been intensely investigated in various cell cultures, including diverse insulinoma cell lines [4-6], by using high concentrations of palmitate (16:0) and oleate (18:1 cis- $\left.\Delta^{9}\right)$, i.e. the major endogenous saturated and monounsaturated fatty acids, respectively.

Growing evidence supports the role of ceramides in the pathogenesis of obesity-related diseases, such as non-alcoholic fatty liver disease (NAFLD) [7], insulin resistance [8] and also type 2 diabetes and its complications [9]. Viability of the $\beta$-cells is also diminished by fatty acids, particularly by the saturated ones, and endoplasmic reticulum (ER) stress has been shown to be involved in this $\beta$-cell lipoapoptosis $[5,10]$. Ceramide synthesis is stimulated by FFA surplus, and it has been implicated in ER-stress-mediated $\beta$-cell lipoapoptosis $[11,12]$.

Fatty acid-induced destructive ER stress largely contributes to $\beta$-cell apoptosis and to reduced insulin secretion [10]. PKR-like ER kinase (PERK), a sensor of the ER stress, phosphorylates eukaryotic initiation factor $2 \alpha$ (eIF2 $\alpha$ ) leading to a general inhibition of translation [13]. Inositol-requiring enzyme 1 (IRE1), another ER stress receptor cuts a short sequence from the $\mathrm{X}$ box-binding protein-1 (XBP-1) mRNA, thus yielding a spliced mRNA (sXBP-1 mRNA), and giving rise to the XBP-1 transcription factor [13]. IRE1 also causes 
activation of c-Jun-N-terminal kinase (JNK), a central stress kinase that promotes both apoptotic cell death [14] and autophagy [15]. The ER-stress-derived induction of C/EBP homologous protein (CHOP), a proapoptotic transcription factor, has been shown to play an important role in $\beta$-cell apoptosis [16].

People ingest considerable amounts of trans fatty acids (TFAs), such as vaccenate (18:1 trans- $\left.\Delta^{11}\right)$, which formed in ruminant animals [17], or elaidate $\left(18: 1\right.$ trans- $\left.\Delta^{9}\right)$ of mostly industrial origin [18]. Dietary TFAs have been shown to exert various deleterious health effects in vivo, and chronic TFA intake has been found to be associated with the risk of type 2 diabetes [19], however very little data is available on the metabolic fate and cellular toxicity of TFAs.

The aim of the present study was to compare the toxicity of the two major dietary TFAs (i.e., elaidate and vaccenate) with that of the best studied endogenous saturated and cisunsaturated fatty acids (i.e., palmitate and oleate, respectively) in RINm5F cells. This rat insulinoma cell line is widely used to investigate $\beta$-cell apoptosis, including lipoapoptosis, and we have also used it successfully to reveal the protective effect of metformin against palmitate induced ER stress and cell death [6]. Cell viability and the intensity of apoptosis and autophagy were assessed, and the underlying ER stress and JNK activation were also monitored. In addition, the intracellular levels of various ceramides and diglycerides as well as the amounts of the relevant fatty acids were determined. Our findings indicated a moderate toxicity of TFAs, which correlated well with the limited accumulation of the potentially deleterious lipid intermediates. Nevertheless, a remarkable difference was observed between the metabolism of endogenous cis and exogenous TFAs, which did not manifest in the short-term cell viability, yet it should be considered in the perspective of chronic in vivo dietary health effects. 


\section{Materials and methods}

\subsection{Materials used}

Culture medium and supplements were purchased from Thermo Scientific (USA). Palmitate, oleate, elaidate, vaccenate, fatty acid free bovine serum albumin, trans-vaccenic acid methyl ester, methyl oleate methyl palmitate, methyl palmitoleate methyl stearate, 1,2-dipalmitoyl-racglycerol (>99\%), 1-palmitoyl-2-oleoyl-sn-glycerol (>99\%), 1,2-dioleoyl-sn-glycerol (>97\%), 1-octadecanoyl-2-hexandecanoyl-sn-glycerol (>99\%), NADH ( $\geq 97 \%)$, and sodium pyruvate (>99\%) were from Sigma Aldrich (St. Louis, MO), n-hexane was purchased from Romil (UK).

C16:0, C17:0, C18:0, C18:1(9Z) (>99\%) ceramides were purchased from Avanti Polar Lipids Inc (Alabaster, AL). Methanol (gradient grade) and acetonitrile (gradient grade) were purchased from Merck (Germany). All other chemicals used in this study were of analytical grade. All experiments and measurements were carried out by using Millipore ultrapure water.

\subsection{Cell culture}

RINm5F rat insulinoma cells were purchased from ATCC (Manassas, VA) and cultured in RPMI 1640 medium, containing $2 \mathrm{mM}$ L-glutamine, $1.5 \mathrm{~g} / 1$ sodium bicarbonate, $4.5 \mathrm{~g} / \mathrm{l}$ glucose, $10 \mathrm{mM}$ HEPES and $1 \mathrm{mM}$ sodium pyruvate and supplemented with $10 \%$ fetal bovine serum and $1 \%$ antibiotics (Thermo Scientific), at $37{ }^{\circ} \mathrm{C}$ in humidified atmosphere containing $5 \% \mathrm{CO}_{2}$

\subsection{Cell treatment with BSA-conjugated fatty acids}

Palmitate, elaidate, oleate and vaccenate (Sigma) were diluted in isopropanol (Molar Chemicals) to a concentration of $50 \mathrm{mM}$, conjugated with $4.16 \mathrm{mM}$ fatty acid free BSA (Sigma) in $1: 4$ ratio, on $37^{\circ} \mathrm{C}$ for 1 hour. The working solution for fatty acid treatments was always prepared freshly in FBS-free and antibiotic-free medium at 0.25 or $0.5 \mathrm{mM}$ final concentration. The culture medium had been replaced by FBS-free and antibiotic-free medium for 1 hour before the cells were treated with fatty acids for $4-24$ hour at $70-80 \%$ confluence in 6 -well 
plates (for western blot, RT-PCR and analysis of ceramides, DGs and fatty acid profile) or in 96-well plates (for cell viability assay and detection of apoptosis and necrosis).

\subsection{Cell viability}

\subsubsection{Colorimetric detection of cell survival and proliferation}

Cell viability was assessed by using the Colorimetric (MTT) Kit for Cell Survival and Proliferation (Millipore, US) according to the manufacturer's instructions. MTT-derived formazan was measured at $530 \mathrm{~nm}$ test and $630 \mathrm{~nm}$ reference wavelengths in a multiscan spectrophotometer (Thermo Scientific). Cell viability was expressed as the percentage of viable cells in the total cell population.

\subsubsection{Detection of necrosis by release of lactate dehydrogenase activity}

Lactate dehydrogenase (LDH) activity as an indicator of necrosis was measured in the cell culture media after $8 \mathrm{~h}$ long fatty acid treatment. Cells were pelleted in the samples by using a benchtop centrifuge $\left(5 \mathrm{~min}, 6,000 \mathrm{rpm}, 4^{\circ} \mathrm{C}\right.$ ), and $500 \mu \mathrm{l}$ cell-free supernatants were mixed with $440 \mu$ l phosphate buffered saline (PBS), $30 \mu \mathrm{l}$ NADH ( $8 \mathrm{mM}$, in PBS), $30 \mu 1$ pyruvate (10 $\mathrm{mM}$, in PBS), and pre-incubated for $5 \mathrm{~min}$ at $37^{\circ} \mathrm{C}$. NADH consumption was monitored by spectrophotometry at $340 \mathrm{~nm}$, for $5 \mathrm{~min}$ in a Varian Cary® $50 \mathrm{UV}$-Vis Spectrophotometer (Agilent Technologies, US). The enzyme activity was expressed as $\mathrm{mU} / \mathrm{ml}$, i.e. nmol NADH oxidized in $1 \mathrm{~min}$ per $1 \mathrm{ml}$ of cell-free medium.

\subsubsection{Detection of apoptosis and necrosis by fluorescence microscopy}

Apoptotic and necrotic cells were detected by using Annexin-V-FLUOS Staining Kit (Roche, $\mathrm{CH})$ and fluorescence microscopy according to the manufacturer's instructions. Cells with green fluorescence (Annexin V labeling) were considered as apoptotic while those with red or both green and red fluorescence (propidium iodide DNA staining) were considered as necrotic. A minimum of 1000 cells was counted in each experimental condition. Apoptosis index was calculated as (number of apoptotic cells) / (number of all cells counted) $\times 100$. 


\subsection{Western blot analysis}

Cells were washed twice with PBS and harvested in $100 \mu 1$ lysis buffer by scraping. The lysis buffer contained $0.1 \%$ SDS, $5 \mathrm{mM}$ EDTA, $150 \mathrm{mM} \mathrm{NaCl}, 50 \mathrm{mM}$ Tris, $1 \%$ Tween $20,1 \mathrm{mM}$ $\mathrm{Na}_{3} \mathrm{VO}_{4}, 1 \mathrm{mM}$ PMSF, $10 \mathrm{mM}$ benzamidine, $20 \mathrm{mM} \mathrm{NaF}, 1 \mathrm{mM}$ pNPP and protease inhibitor cocktail. The lysates were centrifuged in a benchtop centrifuge $\left(10 \mathrm{~min}, 10,000 \mathrm{rpm}, 4{ }^{\circ} \mathrm{C}\right)$. Protein concentration of the supernatant was measured using Pierce BCA Protein Kit Assay (Thermo Scientific), and the samples were stored at $-20{ }^{\circ} \mathrm{C}$ until use.

Samples (20 $\mu$ g protein) were electrophoresed in 10-12-15\% SDS polyacrylamide gels and transferred to PVDF membranes (Millipore). Primary and secondary antibodies were applied overnight at $4{ }^{\circ} \mathrm{C}$ and for $1 \mathrm{~h}$ at room temperature, respectively. Equal protein loading was validated by detection of glyceraldehyde 3-phosphate dehydrogenase (GAPDH), with a mouse monoclonal anti-GAPDH (Santa Cruz, US, sc-32233) antibody, at 1:20,000 dilution, as a constitutively expressed reference protein. Primary antibodies: rabbit anti-BAX (\#2772), rabbit anti-Cleaved Caspase-3 (\#9661), rabbit anti-phospho-eIF2 $\alpha$ (\#9721), rabbit anti-eIF2 $\alpha$ (\#9722), rabbit anti-phospho-SAPK/JNK (THR183/Tyr185) (\#9251S), rabbit anti-SAPK/JNK (\#9252S) from Cell Signaling (US), mouse anti-CHOP (sc-7351), goat anti-GRP78 (sc-1050), rabbit anti-PDI (sc-20132) and goat anti-MAP LC3 $\beta$ (N20) (sc-16755) from Santa Cruz. Secondary antibodies: Horseradish peroxidase (HRP)-conjugated goat anti-rabbit IgG-HRP (\#7074), HRP-conjugated horse anti-mouse IgG-HRP (\#7076) from Cell Signaling and donkey anti-goat IgG-HRP (sc-2020) from Santa Cruz. HRP was detected with chemiluminescence using SuperSignal West Pico Chemiluminescent Substrate (Thermo Scientific).

\subsection{RT-PCR and endonuclease cleavage}

Total RNA was purified from the cells by using RNeasy Plus Mini Kit (Quagen) following the manufacturer's instruction. cDNA was produced by reverse transcription of $0.5 \mu \mathrm{g}$ DNA-free RNA samples using SuperScript III First-Strand Synthesis System for RT-PCR Kit 
(Invitrogen). Spliced and unspliced XBP-1 sequences (421 or $447 \mathrm{bp}$, respectively) were amplified by PCR using iProof High-Fidelity DNA Polymerase Kit (BioRad) and 5' - GCT TGT GAT TGA GAA CCA GG - 3' SY121041268-007 XBP-1 sense (rat) and 5' - AGG CTT GGT GTA TAC ATG G - 3' ST00450236-001 XBP-1 antisense (mouse, rat) primers (Sigma) at thermocycle conditions of $98^{\circ} \mathrm{C} 3 \mathrm{~min}$ followed by 30 cycles of $98{ }^{\circ} \mathrm{C} 10 \mathrm{sec}, 57^{\circ} \mathrm{C} 30 \mathrm{sec}$ and $72{ }^{\circ} \mathrm{C} 15 \mathrm{sec}$ and finished by $72{ }^{\circ} \mathrm{C} 10 \mathrm{~min}$ final extension. PCR products were purified by PEG precipitation. DNA concentration in the PCR products was measured with NanoDrop 1000 Spectrophotometer (Thermo Scientific). For a better visibility, PstI restriction endonuclease cleavage of $200 \mathrm{ng}$ purified PCR product was carried out by using FastDigest PstI (Thermo Scientific) for $30 \mathrm{~min}$ at $37^{\circ} \mathrm{C}$. The unspliced XBP-1 is cut in two fragments (153 and $294 \mathrm{bp}$ ) by PstI while the spliced variant remains uncut [6]. A 234 bp fragment of the GAPDH was also amplified as a reference cDNA using a GAPDH sense primer 5' - AGA CAG CCG CAT CTT CTT GT - 3' and a GAPDH antisense primer 5' - CTT GCC GTG GGT AGA GTC AT - 3'. The PCR thermocycle conditions were $98^{\circ} \mathrm{C} 1 \mathrm{~min}$, then 28 cycles of $98^{\circ} \mathrm{C} 10 \mathrm{sec}, 65^{\circ} \mathrm{C} 30$ sec and $72{ }^{\circ} \mathrm{C} 30 \mathrm{sec}$, completed by a final extension of $72{ }^{\circ} \mathrm{C} 10 \mathrm{~min}$. Equal amounts of DNA samples (i.e. digested XBP-1 or GAPDH) were separated by electrophoresis in $2 \%$ agarose gel and visualized by EtBr staining.

\subsection{Electron microscopy}

For electron microscopy, cells were grown on glass cover slips, and treated at $70-80 \%$ confluence as described above. The medium was removed from the cell cultures, the cells were washed with PBS, and fixed in 3.2\% paraformaldehyde, $0.5 \%$ glutaraldehyde, $1 \%$ sucrose, and $0.028 \% \mathrm{CaCl}_{2}$ in $0.1 \mathrm{M}$ sodium cacodylate, $\mathrm{pH} 7.4$, overnight at $4{ }^{\circ} \mathrm{C}$, and then embedded in Durcupan (Fluka, Switzerland). Ultrathin sections were contrasted with uranyl acetate and with Reynold's lead citrate and examined and photographed in a Jeol JEM-1011 electron microscope, operating at $60 \mathrm{kV}$, equipped with Olympus Morada CCD camera using Olympus 
iTEM (TEM imaging platform) software. Five representative ultrastructural images were selected from the electron microscopic pictures of each treatment. Cytoplasmic areas were measured $\left(70 \mu \mathrm{m}^{2}\right)$ and autophagic structures counted in the images. The data of autophagic structures per cytoplasmic area are presented in a diagram.

\subsection{Analysis of lipid contents}

For fatty acid, ceramide and DG analysis, cells were washed once with PBS, then harvested in $100 \mu 1$ PBS by scraping. The samples were then sedimented in a benchtop centrifuge ( 5 min, 1,500 rpm, $24{ }^{\circ} \mathrm{C}$ ), and the supernatants were discarded. The cells were suspended in PBS, and the protein concentration of the cell suspension was measured as mentioned at western blot analysis. $50 \mu \mathrm{l}$ of each suspension was transferred to a clear crimp vial for GC-FID measurement of fatty acids, and $50 \mu 1$ was transferred to a micro-centrifuge tube for the HPLCMS/MS analysis of DGs and ceramides.

\subsubsection{GC-FID analysis of fatty acid profiles}

$150 \mu \mathrm{l}$ of methanol containing $2 \mathrm{~W} / \mathrm{V} \% \mathrm{NaOH}$ was added to the $50 \mu \mathrm{l}$ cell suspension in the crimp vials, the samples were incubated at $90{ }^{\circ} \mathrm{C}$ for $30 \mathrm{~min}$, and then cooled to room temperature. $400 \mu 1$ of methanol containing $13-15 \%$ of boron trifluoride was added to the samples, and the vials were incubated at $90{ }^{\circ} \mathrm{C}$ for $30 \mathrm{~min}$. After cooling to room temperature, $200 \mu \mathrm{l}$ of saturated $\mathrm{NaCl}$ solution and $300 \mu \mathrm{l}$ of n-hexane were added. Fatty acid methyl esters were extracted to the upper phase containing n-hexane, and this phase was transferred to a vial for GC analysis.

Samples of $1 \mu$ l volume were separated in a Zebron ZB-88 capillary column (60 m x 0.25 mm i.d., $0.20 \mu \mathrm{m}$ film thickness) by using a Shimadzu GC-2014 gas chromatograph equipped with a Shimadzu AOC-20s autosampler and a flame ionization detector (FID). The carrier gas was hydrogen at $35 \mathrm{~cm} / \mathrm{sec}$ velocity. The injector and detector temperature was $250{ }^{\circ} \mathrm{C}$, and the oven temperature was ramped from $100{ }^{\circ} \mathrm{C}$ to $210{ }^{\circ} \mathrm{C}$ at a rate of $4{ }^{\circ} \mathrm{C} / \mathrm{min}$. 


\subsubsection{HPLC-MS/MS analysis of diglycerides and ceramides}

The cells were pelleted by centrifugation $\left(5 \mathrm{~min}, 1,500 \mathrm{rpm}, 24^{\circ} \mathrm{C}\right.$ ) and resuspended in methanol containing ceramide 17:0 internal standard $(50 \mathrm{ng} / \mathrm{ml})$. The samples were homogenized with an ultrasonic sonotrode and centrifuged (10 min, 13,400 rpm, $\left.24^{\circ} \mathrm{C}\right)$. The supernatants were transferred to vials for HPLC-MS/MS analysis.

$10 \mu \mathrm{l}$ samples were injected in the HPLC composed of a Perkin Elmer series 200 high pressure gradient pump, autosampler, online degasser and a thermostat. A Kinetex ${ }^{\circledR} 5 \mu \mathrm{m}$, C8 $100 \AA$, LC (100 x 3 mm) column was used with a gradient elution of methanol (mobile phase A) and $10 \mathrm{mM}$ ammonium-acetate (mobile phase B): 0 min at $90 \% \mathrm{~A} ; 1$ min at $90 \% \mathrm{~A}$; 9 min at $95 \% \mathrm{~A} ; 10.5 \mathrm{~min}$ at $98 \% \mathrm{~A} ; 11.5 \mathrm{~min}$ at $98 \% \mathrm{~A} ; 12 \mathrm{~min}$ at $90 \% \mathrm{~A} ; 14 \mathrm{~min}$ at $90 \% \mathrm{~A}$. Ceramide and diglyceride species were detected using a triple quadrupole mass spectrometer (Applied Biosystems MDS SCIEX 4000 Q TRAP). The instrument was used in positive multiple reaction monitoring mode. The ion spray temperature was set to $400{ }^{\circ} \mathrm{C}$ and the voltage to $5500 \mathrm{~V}$.

\subsection{Statistics}

The results of western blot analyses and DNA gel electrophoresis were carried out by densitometry using ImageQuant 5.2 software and are shown as relative band densities normalized to a GAPDH as a reference protein or cDNA. Data are presented in the diagrams as mean values \pm S.D. and were compared by ANOVA with Tukey's multiple comparison post hoc test using GraphPad Prism 6 software. Differences of a P value below 0.01 were considered to be statistically significant.

\section{Results}

\subsection{Effects of various fatty acids on RINm5F cell viability}

Palmitate toxicity has been investigated in RINm5F cells in our laboratory [6, 20]. Based on our previous experience, RINm5F cell survival was assessed after $24 \mathrm{~h}$ long treatments with 
different fatty acids at 250 or $500 \mu \mathrm{M}$ concentration by using MTT assay. In accordance with several earlier observations, palmitate was found to decrease the number of viable cells effectively, and in a dose dependent manner. Viability dropped to about $40 \%$ and below $20 \%$ of the control value upon 250 and $500 \mu \mathrm{M}$ palmitate doses, respectively (Fig. 1A). The damage caused by oleate treatment was found to be much milder as demonstrated in several earlier studies, however the comparison of the three investigated unsaturated fatty acids revealed none of the predicted differences. Unsaturated fatty acids, either cis or trans, failed to cause a significant change in the viability at $250 \mu \mathrm{M}$ concentration, and their toxicity remained uniformly far below that of palmitate at $500 \mu \mathrm{M}$ level as they only reduced the number of viable cells to about $70 \%$ of the control (Fig. 1A).

To reveal the contribution of necrotic and apoptotic cell death in the observed decrease in cell viability, the release of LDH as a widely used marker of necrosis [21] was examined in the cell media, and the apoptotic index, i.e. the number of apoptotic cells among 100 total cells was determined by using fluorescence microscopy after $8 \mathrm{~h}$ fatty acid treatment. A small and almost uniform elevation in LDH activity (to about $12 \mathrm{mU} / \mathrm{ml}$ ) was detected in the media of all the fatty acid-treated cells (Fig. 1B), which indicates that in spite of a low necrosis inducing effect of the high concentration fatty acid treatments, the marked difference observed in cell viability (Fig. 1A) cannot be due to different necrotic activities. Apoptosis detection, in contrast, revealed an obvious difference between palmitate and the other investigated fatty acids, as only the palmitate-treated cells showed a 5-fold increase in the frequency of apoptosis (Fig. 2). The three unsaturated fatty acids caused a small and statistically not significant elevation in the apoptotic index when compared to the control level.

The diverse effects of different fatty acids on the intensity of apoptosis were further supported by comparing caspase-3 activation in the cells. According to the much greater number of apoptotic cells, the amount of cleaved caspase-3 was found to be increased more 
than 10-fold by palmitate treatment (Fig. 3A). The cells treated with one of the unsaturated fatty acids contained slightly more cleaved caspase-3 than the control BSA-treated cells, and this was particularly conspicuous in case of vaccenate, however, statistical analysis deemed these differences non-significant (Fig. 3A). The level of proapoptotic Bax protein was not affected significantly by any of the investigated fatty acids in our experiments (Fig. 3B).

\subsection{Induction of ER stress}

ER stress contributes to the cellular mechanism of lipotoxicity, and it initiates signaling pathways that stimulate apoptosis and autophagy. Excision of 26 nucleotides from the XBP-1 mRNA and phosphorylation of eIF2 $\alpha$ translational initiation factor are early events of the unfolded protein response (UPR) as they are catalyzed directly by the ER stress receptors IRE1 and PERK, respectively. The spliced (sXBP-1) mRNA serves as a template for a transcription factor, and its appearance is a specific marker of the ER stress and the UPR. This IRE-1 mediated splicing was largely enhanced in palmitate treated cells, where the level of sXBP-1 mRNA more than doubled, and the ratio of sXBP-1/uXBP-1 increased more than 5-fold $(0.77$ \pm 0.16 in palmitate treated v.s. $0.15 \pm 0.06$ in control cells), which indicates a massive induction of the ER stress response (Fig. 4A). Cis and trans unsaturated fatty acids, in turn, only caused a minor and insignificant elevation of the sXBP-1 mRNA level or the sXBP-1/uXBP-1 ratio compared to control (Fig. 4A). Intensity of PERK-mediated eIF2 $\alpha$ phosphorylation was assessed by comparing the levels of phosphorylated and overall eIF2 $\alpha$ protein, and it was found to be increased significantly in the palmitate-treated cells only (Fig. 4B).

Induction of CHOP is also a specific and sensitive marker of ER stress in the cells. All the four investigated fatty acids caused a significant elevation in CHOP expression. Palmitate proved to be the most effective again as it increased CHOP level more than 3 -fold, while the unsaturated fatty acids resulted in a 2-fold induction (Fig. 4C). Increased expression of ER chaperons is an important adaptive element of the UPR, which usually develops with a delay. 
The levels of two major ER chaperons, BiP and PDI as long-term markers of the ER stress were examined by immunoblotting, however, the $8 \mathrm{~h}$ long fatty acid treatments did not cause any obvious alterations in the amount of these proteins in our experiments (Fig. 5).

\subsection{JNK phosphorylation and autophagy}

JNK is a major stress kinase, which is sensitive among others to oxidative and ER stresses, and hence it is also affected by lipotoxicity. The enzyme is activated by phosphorylation and it promotes apoptosis and autophagy. Phosphorylated JNK isoforms were detected by western blot using a phosphorylation-specific anti-P-JNK antibody. A remarkable, more than 5-fold increase was found in palmitate-treated cells, while the three unsaturated fatty acids caused a much smaller increase in JNK phosphorylation (Fig. 6).

Formation of the autophagic vacuoles involves the conjugation of phosphatidylethanolamine to microtubule-associated protein 1A/1B-light chain 3 (LC3), and it converts the cytosolic form (LC3-I) to a membrane-associated form (LC3-II) of the protein. The ratio of LC3-II to LC3-I and even more often the amount of LC3-II are used as markers to monitor autophagy [22]. The complex mutual interaction between ER stress, JNK activation and autophagy, as well as the role of autophagy in $\beta$-cell failure in type 2 diabetes remain to be elucidated $[10,23]$. Stimulation of autophagy was first investigated through assessing the two forms of LC3 by immunoblot in our experiments. Palmitate was the most effective again but all the four fatty acids caused some increase in LC3-II level, although the change was not significant in case of elaidate $(\mathrm{P}=0.1413)$. Palmitate-treatment doubled the calculated LC3II/LC3-I ratio compared to the control value (Fig. 7).

\subsection{Effects of various fatty acids on cellular ultrastructure}

Morphological signs of ER damage, ER stress and intensified autophagy were sought by electron microscopy in the RINm5F cells after $8 \mathrm{~h}$ long treatment with fatty acids. The cytoplasm of control cells looked normal with mitochondria, numerous, parallel rough ER 
cisternae, Golgi apparatus and secretory granules. There were very few old, dense autophagic vacuoles (Figs. 8 and 9 control).

While rough ER morphology did not change significantly in elaidate-, oleate- or vaccenate-treated cells, the ultrastructural signs of deranged ER morphology, i.e. shorter and scattered cisternae were indicative of the presence of severe organelle stress in palmitate treated cells (Fig. 8, panels of treated cells). Mitochondria did not show any defects upon fatty acid treatments (Fig. 8, panels of treated cells).

All the four fatty acids caused some increase in autophagy. Many phagophores, newly formed autophagosomes and light autophagic vacuoles were observable. The autophagic activity was mostly enhanced in palmitate treated cells (Fig. 9, panels of treated cells and diagram).

\subsection{Fatty acid profile of the cells}

Internalization of the investigated fatty acids into the cellular lipids was assessed by monitoring the changes in the fatty profile of the cells during $24 \mathrm{~h}$ long incubations. Extracellular fatty acids were removed by rinsing the adherent cells, and the most relevant saturated and monounsaturated fatty acids were measured by GC-FID after saponification of complex lipids. All the four fatty acids were effectively internalized by the cells, though with different time courses, palmitate reached its peak level at $8 \mathrm{~h}$ while the levels of unsaturated fatty acids increased gradually through the $24 \mathrm{~h}$ of incubation (Fig. 10). The amount of palmitate and elaidate increased by about $150 \mu \mathrm{g} / \mathrm{mg}$ protein, that of oleate and vaccenate increased by about $100 \mu \mathrm{g} / \mathrm{mg}$ protein above the control levels. Since the cells contained substantial amounts (nearly $50 \mu \mathrm{g} / \mathrm{mg}$ protein) of palmitate and oleate originally, but they had no detectable quantity of TFAs, palmitate reached the highest (above $200 \mu \mathrm{g} / \mathrm{mg}$ protein) and vaccenate reached the lowest (below $100 \mu \mathrm{g} / \mathrm{mg}$ protein) level among the four fatty acids added. 
A slight elevation of cis-palmitoleate $\left(16: 1 \operatorname{cis}-\Delta^{9}\right)$ and stearate in the palmitate-treated cells was indicative of intensified desaturation and elongation of the administered fatty acid, respectively. Interestingly, the addition of either TFAs caused an obvious accumulation of its degradation intermediate $\left(16: 1\right.$ trans $-\Delta^{7}$ or $16: 1$ trans $-\Delta^{9}$ in case of elaidate or vaccenate, respectively) in a striking contrast to oleate as the concentration of $16: 1$ cis- $\Delta^{7}$ fatty acid did not increase in oleate-treated cells (Fig. 10).

\subsection{Diglyceride levels in the cells}

Synthesis of triglycerides is a potent mechanism for the cell to drain an acyl-CoA surplus, but an unbalanced supply of saturated and unsaturated fatty acids can clog the pathway and hence lead to DG accumulation. LC-MS/MS measurement of the most abundant and most relevant DG species containing 16 and 18 carbon long saturated and mono-unsaturated fatty acids indeed revealed a marked buildup of certain intermediates. The greatest increase in the levels of 1,2-dipalmitoyl-glycerol (16:0/16:0), 1-palmitoyl-2-stearoyl-glycerol (16:0/18:0), 1,2-distearoyl-glycerol (18:0/18:0) and 1-palmitoyl-2-palmitoleoyl-glycerol (16:0/16:1) was 50-fold, 18-fold, 12-fold and 5-fold, respectively at $8 \mathrm{~h}$ of palmitate treatment (Fig. 11). A milder but still remarkable elevation was also found in the levels of the other DGs, except for 1,2-dioleoyl-glycerol (18:1/18:1), which decreased to half of the control value. Taken these changes together, the overall DG content of the cells was elevated nearly 17 fold at this point $(95.1 \pm 7.4 \mu \mathrm{g} / \mathrm{mg}$ protein v.s. $5.7 \pm 0.41 \mu \mathrm{g} / \mathrm{mg}$ protein in palmitate-treated and control, respectively).

The effects of oleate treatment were in striking contrast to those of palmitate. The increase in overall DG level was the largest at $4 \mathrm{~h}$ of oleate treatment, when its trebling $(9.9 \pm 0.84$ $\mu \mathrm{g} / \mathrm{mg}$ protein v.s. $3.2 \pm 0.29 \mu \mathrm{g} / \mathrm{mg}$ protein in oleate-treated and control, respectively) was mostly due to an 18-fold increase in 1,2-dioleoyl-glycerol (18:1/18:1) content and to a lesser extent to a 2-fold increase in 1-palmitoyl-2-oleoyl-glycerol (16:0/18:1) and 1-stearoyl-2-oleoyl- 
glycerol (18:0/18:1) (Fig. 11). It is also noteworthy that the amounts of those four DGs, i.e., 1,2-dipalmitoyl-glycerol $\quad(16: 0 / 16: 0), \quad 1$-palmitoyl-2-stearoyl-glycerol $\quad(16: 0 / 18: 0)$, 1,2-distearoyl-glycerol (18:0/18:0) and 1-palmitoyl-2-palmitoleoyl-glycerol (16:0/16:1), which are the most markedly elevated in palmitate-treated cells, were found to be 5-10-fold decreased in oleate-treated cells at all times. Similar changes were seen in the cells treated with either TFAs. The overall DG accumulation was slightly more pronounced, but remained far below that induced by palmitate: they were 5 -fold $(14.8 \pm 1.13 \mu \mathrm{g} / \mathrm{mg}$ protein v.s. $3.2 \pm 0.29 \mu \mathrm{g} / \mathrm{mg}$ protein) and 6-fold $(18.0 \pm 1.67 \mu \mathrm{g} / \mathrm{mg}$ protein v.s. $3.2 \pm 0.29 \mu \mathrm{g} / \mathrm{mg}$ protein $)$ in case of elaidate and vaccenate, respectively at $4 \mathrm{~h}$ of incubation, and it was mostly due to a $27-28$-fold increase in the levels of DGs containing only elaidate, vaccenate or oleate (18:1/18:1). The accumulation of 1-palmitoyl-2-elaidyl-glycerol and 1-palmitoyl-2-vaccenyl-glycerol was also more noticeable than that of 1-palmitoyl-2-oleoyl-glycerol (16:0/18:1) (Fig. 11).

\subsection{Ceramide levels in the cells}

Ceramides are potentially toxic lipid intermediates that contain one fatty acyl chain condensed with sphingosine. Excess acyl-CoA can stimulate ceramide production through an enhanced acylation in de novo synthesis or a salvage pathway. This phenomenon was assessed in our experiments by a quantitative determination of those ceramides that contain either of the four investigated fatty acids by using LC-MS/MS analysis of the cell samples. The dominant ceramides in control, BSA-treated cells were palmitoyl- and stearoyl-sphingosines (16:0 and 18:0) of about $1 \mu \mathrm{g} / \mathrm{mg}$ protein and $250 \mathrm{ng} / \mathrm{mg}$ protein levels, respectively while oleoylsphingosine (18:1) was hardly detectable (around $10 \mathrm{ng} / \mathrm{mg}$ protein). Palmitate treatment caused a 6-fold elevation in the overall level of the measured ceramides, which peaked at 8 and $16 \mathrm{~h}$ of incubation. This effect was due to a 5-6-fold increase in palmitoyl- (16:0) and to a 6-8fold increase in stearoyl- (18:0) sphingosine content, while the oleoyl- (18:1) sphingosine level did not change (Fig. 12). 
In line with its smaller cytotoxicity, oleate increased the overall ceramide level much less. Although some oleoyl-sphingosine (18:1) gathered in the cells $(66.0 \pm 4.2 \mathrm{ng} / \mathrm{mg}$ protein v.s. $12.2 \pm 1.0 \mathrm{ng} / \mathrm{mg}$ protein at $24 \mathrm{~h}$ in oleate-treated and control cells, respectively), the amounts of the more dominant ceramide species did not change (palmitoyl-sphingosine, 16:0) or decreased to less than half of control level (stearoyl-sphingosine, 18:0) (Fig. 12). The most intriguing difference between cis-oleate and the two TFAs was seen at the formation of elaidyland vaccenyl-sphingosines, which was an order of magnitude above that of oleoyl-sphingosine. An increment of $658.4 \pm 57.3 \mathrm{ng} / \mathrm{mg}$ protein elaidyl-sphingosine, $431.4 \pm 37.9 \mathrm{ng} / \mathrm{mg}$ protein vaccenyl-sphingosine and $53.8 \pm 5.1 \mathrm{ng} / \mathrm{mg}$ protein oleoyl-sphingosine was found at $24 \mathrm{~h}$ in the elaidate-, vaccenate- and oleate-treated cells, respectively. Since the three unsaturated fatty acids had otherwise similar effects on the dominant ceramide species, these differences were also reflected by the alterations of overall ceramide level: it nearly doubled in the TFA-treated cells and increased by only $30 \%$ in oleate-treated cells by the end of the experiments (Fig. 12).

\section{Discussion}

Lipotoxicity has received a growing attention in the past decade, and it became evident that elevated FFA levels are detrimental to a wide variety of cells and tissues. The cell damage, which is caused by FFA surplus, contributes to the development of obesity related pathologies, such as cardiovascular diseases, the metabolic syndrome and type 2 diabetes. Long chain FFAs in the blood plasma derive from mobilization of fat depots, which is stimulated by inflammation in the hypertrophic adipose tissue [3]. A chronic exposure to excess fatty acids interferes with insulin signaling in the hormone target cells mostly via serine phosphorylation of insulin receptor substrate (IRS) proteins by various serine kinases [24]. The developing insulin resistance demands enhancement of insulin secretion from the pancreatic $\beta$-cells as a compensation, which induces an adaptive ER stress in these cells. However, $\beta$-cells themselves are also affected by lipotoxicity, and the aggravated ER stress may become destructive. 
Mounting evidence supports the central role of ER stress-mediated $\beta$-cell apoptosis in the development of type 2 diabetes $[10,16]$.

It is intriguing that the unsaturated oleate is generally less toxic than the saturated palmitate $[11,25]$, which is probably due to a disability of the cells to efficiently channel saturated fatty acids into biosynthetic pathways in the lack of proportional amounts of unsaturated ones [26]. Our results strengthen this assumption as palmitate treatment resulted in a large, approximately 17 -fold accumulation of DGs, which were mostly the species containing two saturated fatty acyl chains that are normally under-represented in the control cells, i.e. dipalmitoyl-, palmitoyl- stearoyl- and distearoyl-glycerols (Fig. 11). The mono-unsaturated fatty acids caused a much less pronounced increase in DG levels, and it was restricted to those containing one or two chains of the given unsaturated fatty acid. Nevertheless, the amount of these DGs reached remarkably higher concentrations in the TFA-treated cells, which might suggest a hindrance of third acylation in the presence of such fatty acids in the intermediate, and this assumption deserves to be further investigated.

Ceramides are central intermediates of sphingolipid metabolism, which play an important role in the lipotoxicity developing in metabolic disorders [27]. Fatty acid treatment can be expected to enhance ceramide production because fatty acyl-CoAs are utilized in both de novo synthesis [28] and salvage [29] of ceramide. A deleterious ceramide production was indeed demonstrated in palmitate-treated MIN6 mouse insulinoma cells and in human islets [30]. We also found a several-fold increase in ceramide content of palmitate-treated RINm5F cells, the concentrations of palmitoyl- and stearoyl-sphingosines elevated 3-6 times at different times of incubation. Although unsaturated fatty acids, either cis or trans, caused only a small change in the overall amount of ceramides, the appearance of elaidyl- and vaccenyl-sphingosines was remarkable, and intriguingly it largely overgrew the amount of oleoyl-sphingosine. Whether this is due to a higher affinity of sphingosine acyltransferases to TFAs or to a less efficient 
utilization of TFA-containing ceramides in the diverse biosynthetic reactions, perhaps due to a favorable usage of TFAs by ceramide synthases, it remains to be elucidated. Nonetheless, it is noteworthy that long term TFA supply might maintain slightly higher intracellular ceramide levels, and thus dietary TFAs can induce more pronounced ceramide toxicity than the endogenous cis-unsaturated fatty acids.

Chronic TFA intake was suggested to be associated with the risk of type 2 diabetes [19], but several in vivo studies indicated neutral or beneficial effects of TFA ingestion; and suggested a protective role of vaccenate $\left(18: 1\right.$ trans- $\left.\Delta^{11}\right)$ and trans-palmitoleate $\left(16: 1\right.$ trans- $\left.-\Delta^{9}\right)$ against diabetes [31, 32]. In spite of the evident need for better insight and understanding, the putative toxicity of TFAs has been scarcely investigated at cellular and molecular levels. A recent study has revealed that TFAs enhanced extracellular ATP-induced apoptosis in a macrophage-like cell line, RAW264.7, and it was accompanied by elevated activation of the apoptosis signal-regulating kinase 1 (ASK1) - p38 MAP kinase pathway [33]. Efficient incorporation of TFAs in cellular lipids has also been reported recently in a study using endothelial (HUVEC) and hepatoma (HepG2) cells. It has been shown that TFAs suppress TNF- $\alpha$-induced inflammatory gene expression in these two cell lines [34].

Trans-palmitoleate (16:1 trans- $\left.\Delta^{9}\right)$, which has been found to be beneficial in various studies [31, 35], is not only ingested with ruminant-derived food but it is also produced endogenously as a partially degraded intermediate of vaccenate (18:1 trans- $\left.\Delta^{11}\right)$ [36]. The shortened derivatives of vaccenate and elaidate, i.e. the above mentioned trans-palmitoleate (16:1 trans- $\left.-\Delta^{9}\right)$ and its positional isomer $\left(16: 1\right.$ trans- $\left.-\Delta^{7}\right)$, respectively, were also found to be elevated in the TFA-treated insulinoma cells in our experiments (Fig. 10), and they were likely produced as intermediates of $\beta$-oxidation. It is noteworthy that the analogous cis intermediate of $\beta$-oxidation (16:1 cis- $\left.\Delta^{7}\right)$ was not elevated in the oleate-treated cells in spite of higher intracellular oleate contents. 
The two investigated TFAs showed greater similarity to oleate than to palmitate with respect to both toxicity and incorporation in complex lipids in our study. Thus their behavior further strengthens the correlation between the accumulation of certain lipid intermediates, such as ceramides and DGs and the intensity of cell damage. The TFA-triggered buildup of ceramides and DGs was much smaller than the accumulations seen in palmitate-treated cells, and it was not enough to induce apoptosis in our short incubations. We also detected the production of trans-palmitoleate in the TFA-treated cells, and this intermediate is considered to be protective against lipotoxicity. These findings do not support either the deleterious health effects of TFAs in general, nor the often suggested difference between the industrial elaidate and the natural vaccenate. It is true, however, that diabetes is not the only pathology, which has been suspected to be associated to TFA consumption, and $\beta$-cells are not the only potential targets of TFA toxicity. Therefore, similar experiments need to be undertaken by using various cell lines, which are relevant for metabolic disorders and cardiovascular diseases. Our results also revealed some interesting differences between the metabolism of TFAs and oleate, which were not reflected in the short-term toxicity but might be important in the long run for the health effects of chronic consumption of dietary fatty acids.

\section{Acknowledgment}

We thank Mrs. Valéria Mile and Sarolta Pálfia for skilful technical assistance. This work was supported by the Hungarian National Research, Development and Innovation Office (NKFIH grant number: K 125201) and by the Higher Education Excellence Program of the Ministry of Human Capacities in the frame of Biotechnology research area of Budapest University of Technology and Economics (BME FIKP-BIO). Éva Kereszturi is a grantee of the János Bolyai Research Scholarship of the Hungarian Academy of Sciences. 


\section{References}

1. Cooper DE, Young PA, Klett EL, Coleman RA. Physiological Consequences of Compartmentalized Acyl-CoA Metabolism. J Biol Chem. 2015;290(33):20023-31. doi: 10.1074/jbc.R115.663260. PubMed PMID: 26124277; PubMed Central PMCID: PMCPMC4536410.

2. Schaffer JE. Lipotoxicity: Many Roads to Cell Dysfunction and Cell Death: Introduction to a Thematic Review Series. J Lipid Res. 2016;57(8):1327-8. doi: 10.1194/jlr.E069880. PubMed PMID: 27260998; PubMed Central PMCID: PMCPMC4959852.

3. Csala M. [Hyper-free fatty acidemia - insulin resistance and beta-cell death]. Orv Hetil. 2016;157(19):733-9. doi: 10.1556/650.2016.30439. PubMed PMID: 27133272.

4. Karaskov E, Scott C, Zhang L, Teodoro T, Ravazzola M, Volchuk A. Chronic palmitate but not oleate exposure induces endoplasmic reticulum stress, which may contribute to INS-1 pancreatic beta-cell apoptosis. Endocrinology. 2006;147(7):3398-407. doi: 10.1210/en.2005-1494. PubMed PMID: 16601139.

5. Lai E, Bikopoulos G, Wheeler MB, Rozakis-Adcock M, Volchuk A. Differential activation of ER stress and apoptosis in response to chronically elevated free fatty acids in pancreatic beta-cells. Am J Physiol Endocrinol Metab. 2008;294(3):E540-50. doi: 10.1152/ajpendo.00478.2007. PubMed PMID: 18198352.

6. Simon-Szabo L, Kokas M, Mandl J, Keri G, Csala M. Metformin attenuates palmitateinduced endoplasmic reticulum stress, serine phosphorylation of IRS-1 and apoptosis in rat insulinoma cells. PLoS One. 2014;9(6):e97868. doi: 10.1371/journal.pone.0097868. PubMed PMID: 24896641; PubMed Central PMCID: PMCPMC4045581.

7. Pagadala M, Kasumov T, McCullough AJ, Zein NN, Kirwan JP. Role of ceramides in nonalcoholic fatty liver disease. Trends Endocrinol Metab. 2012;23(8):365-71. doi: 
10.1016/j.tem.2012.04.005. PubMed PMID: 22609053; PubMed Central PMCID: PMCPMC3408814.

8. Konstantynowicz-Nowicka K, Harasim E, Baranowski M, Chabowski A. New evidence for the role of ceramide in the development of hepatic insulin resistance. PLoS One. 2015;10(1):e0116858. doi: 10.1371/journal.pone.0116858. PubMed PMID: 25635851; PubMed Central PMCID: PMCPMC4312035.

9. Galadari S, Rahman A, Pallichankandy S, Galadari A, Thayyullathil F. Role of ceramide in diabetes mellitus: evidence and mechanisms. Lipids Health Dis. 2013;12:98. doi: 10.1186/1476-511X-12-98. PubMed PMID: 23835113; PubMed Central PMCID: PMCPMC3716967.

10. Oh YS, Bae GD, Baek DJ, Park EY, Jun HS. Fatty Acid-Induced Lipotoxicity in Pancreatic Beta-Cells During Development of Type 2 Diabetes. Front Endocrinol (Lausanne). 2018;9:384. doi: 10.3389/fendo.2018.00384. PubMed PMID: 30061862; PubMed Central PMCID: PMCPMC6054968.

11. Boslem E, MacIntosh G, Preston AM, Bartley C, Busch AK, Fuller M, et al. A lipidomic screen of palmitate-treated MIN6 beta-cells links sphingolipid metabolites with endoplasmic reticulum (ER) stress and impaired protein trafficking. Biochem $\mathrm{J}$. 2011;435(1):267-76. doi: 10.1042/BJ20101867. PubMed PMID: 21265737.

12. Veret J, Coant N, Berdyshev EV, Skobeleva A, Therville N, Bailbe D, et al. Ceramide synthase 4 and de novo production of ceramides with specific $\mathrm{N}$-acyl chain lengths are involved in glucolipotoxicity-induced apoptosis of INS-1 beta-cells. Biochem J. 2011;438(1):177-89. doi: 10.1042/BJ20101386. PubMed PMID: 21592087.

13. Mandl J, Meszaros T, Banhegyi G, Csala M. Minireview: endoplasmic reticulum stress: control in protein, lipid, and signal homeostasis. Mol Endocrinol. 2013;27(3):384-93. doi: 10.1210/me.2012-1317. PubMed PMID: 23349523. 
14. Lei K, Davis RJ. JNK phosphorylation of Bim-related members of the Bcl2 family induces Bax-dependent apoptosis. Proc Natl Acad Sci U S A. 2003;100(5):2432-7. doi: 10.1073/pnas.0438011100. PubMed PMID: 12591950; PubMed Central PMCID: PMCPMC151358.

15. Li DD, Wang LL, Deng R, Tang J, Shen Y, Guo JF, et al. The pivotal role of c-Jun NH2terminal kinase-mediated Beclin 1 expression during anticancer agents-induced autophagy in cancer cells. Oncogene. 2009;28(6):886-98. doi: 10.1038/onc.2008.441. PubMed PMID: 19060920.

16. Mandl J, Meszaros T, Banhegyi G, Hunyady L, Csala M. Endoplasmic reticulum: nutrient sensor in physiology and pathology. Trends Endocrinol Metab. 2009;20(4):194-201. doi: 10.1016/j.tem.2009.01.003. PubMed PMID: 19349192.

17. Jenkins TC. Lipid metabolism in the rumen. J Dairy Sci. 1993;76(12):3851-63. doi: 10.3168/jds.S0022-0302(93)77727-9. PubMed PMID: 8132891.

18. Kuhnt K, Baehr M, Rohrer C, Jahreis G. Trans fatty acid isomers and the trans-9/trans11 index in fat containing foods. Eur J Lipid Sci Technol. 2011;113(10):1281-92. doi: 10.1002/ejlt.201100037. PubMed PMID: 22164125; PubMed Central PMCID: PMCPMC3229980.

19. Salmeron J, Hu FB, Manson JE, Stampfer MJ, Colditz GA, Rimm EB, et al. Dietary fat intake and risk of type 2 diabetes in women. Am J Clin Nutr. 2001;73(6):1019-26. doi: 10.1093/ajcn/73.6.1019. PubMed PMID: 11382654.

20. Simon-Szabo L, Kokas M, Greff Z, Boros S, Banhegyi P, Zsakai L, et al. Novel compounds reducing IRS-1 serine phosphorylation for treatment of diabetes. Bioorg Med Chem Lett. 2016;26(2):424-8. doi: 10.1016/j.bmcl.2015.11.099. PubMed PMID: 26704265. 
21. Chan FK, Moriwaki K, De Rosa MJ. Detection of necrosis by release of lactate dehydrogenase activity. Methods Mol Biol. 2013;979:65-70. doi: 10.1007/978-1-62703290-2_7. PubMed PMID: 23397389; PubMed Central PMCID: PMCPMC3763497.

22. Mizushima N, Yoshimori T. How to interpret LC3 immunoblotting. Autophagy. 2007;3(6):542-5. PubMed PMID: 17611390.

23. Zhang E, Lu X, Yin S, Yan M, Lu S, Fan L, et al. The functional role of Bax/Bak in palmitate-induced lipoapoptosis. Food Chem Toxicol. 2018;123:268-74. doi: 10.1016/j.fct.2018.11.011. PubMed PMID: 30408539.

24. Capurso C, Capurso A. From excess adiposity to insulin resistance: the role of free fatty acids. Vascul Pharmacol. 2012;57(2-4):91-7. doi: 10.1016/j.vph.2012.05.003. PubMed PMID: 22609131.

25. Palomer X, Pizarro-Delgado J, Barroso E, Vazquez-Carrera M. Palmitic and Oleic Acid: The Yin and Yang of Fatty Acids in Type 2 Diabetes Mellitus. Trends Endocrinol Metab. 2018;29(3):178-90. doi: 10.1016/j.tem.2017.11.009. PubMed PMID: 29290500.

26. Zambo V, Simon-Szabo L, Szelenyi P, Kereszturi E, Banhegyi G, Csala M. Lipotoxicity in the liver. World J Hepatol. 2013;5(10):550-7. doi: 10.4254/wjh.v5.i10.550. PubMed PMID: 24179614; PubMed Central PMCID: PMCPMC3812457.

27. Chaurasia B, Summers SA. Ceramides - Lipotoxic Inducers of Metabolic Disorders. Trends Endocrinol Metab. 2015;26(10):538-50. doi: 10.1016/j.tem.2015.07.006. PubMed PMID: 26412155.

28. Futerman AH, Riezman H. The ins and outs of sphingolipid synthesis. Trends Cell Biol. 2005;15(6):312-8. doi: 10.1016/j.tcb.2005.04.006. PubMed PMID: 15953549.

29. Hait NC, Oskeritzian CA, Paugh SW, Milstien S, Spiegel S. Sphingosine kinases, sphingosine 1-phosphate, apoptosis and diseases. Biochim Biophys Acta. 
2006;1758(12):2016-26. doi: 10.1016/j.bbamem.2006.08.007. PubMed PMID: 16996023.

30. Manukyan L, Ubhayasekera SJ, Bergquist J, Sargsyan E, Bergsten P. Palmitate-induced impairments of beta-cell function are linked with generation of specific ceramide species via acylation of sphingosine. Endocrinology. 2015;156(3):802-12. doi: 10.1210/en.20141467. PubMed PMID: 25535826.

31. de Souza RJ, Mente A, Maroleanu A, Cozma AI, Ha V, Kishibe T, et al. Intake of saturated and trans unsaturated fatty acids and risk of all cause mortality, cardiovascular disease, and type 2 diabetes: systematic review and meta-analysis of observational studies. BMJ. 2015;351:h3978. doi: 10.1136/bmj.h3978. PubMed PMID: 26268692; PubMed Central PMCID: PMCPMC4532752.

32. Wang X, Gupta J, Kerslake M, Rayat G, Proctor SD, Chan CB. Trans-11 vaccenic acid improves insulin secretion in models of type 2 diabetes in vivo and in vitro. Molecular nutrition \& food research. 2016;60(4):846-57. doi: 10.1002/mnfr.201500783. PubMed PMID: 27061233.

33. Hirata Y, Takahashi M, Kudoh Y, Kano K, Kawana H, Makide K, et al. trans-Fatty acids promote proinflammatory signaling and cell death by stimulating the apoptosis signalregulating kinase 1 (ASK1)-p38 pathway. J Biol Chem. 2017;292(20):8174-85. doi: 10.1074/jbc.M116.771519. PubMed PMID: 28360100; PubMed Central PMCID: PMCPMC5437226.

34. Da Silva MS, Julien P, Bilodeau JF, Barbier O, Rudkowska I. Trans Fatty Acids Suppress TNF-alpha-Induced Inflammatory Gene Expression in Endothelial (HUVEC) and Hepatocellular Carcinoma (HepG2) Cells. Lipids. 2017;52(4):315-25. doi: 10.1007/s11745-017-4243-4. PubMed PMID: 28315997. 
35. Kleber ME, Delgado GE, Lorkowski S, Marz W, von Schacky C. Trans-fatty acids and mortality in patients referred for coronary angiography: the Ludwigshafen Risk and Cardiovascular Health Study. Eur Heart J. 2016;37(13):1072-8. doi: 10.1093/eurheartj/ehv446. PubMed PMID: 26396230.

36. Jaudszus A, Kramer R, Pfeuffer M, Roth A, Jahreis G, Kuhnt K. trans Palmitoleic acid arises endogenously from dietary vaccenic acid. Am J Clin Nutr. 2014;99(3):431-5. doi: 10.3945/ajcn.113.076117. PubMed PMID: 24429537. 


\section{FIGURE LEGENDS}

Fig. 1. Cell viability and $\mathrm{LDH}$ release. A: RINm5F rat insulinoma cells were treated with BSA (Control) or BSA-conjugated fatty acids $(250$ or $500 \mu \mathrm{M})$ for 24 hours. Cell viability was assessed by Colorimetric (MTT) Kit for Cell Survival and Proliferation (Millipore) and expressed as the percentage of Control. B: The cells were treated with fatty acids $(500 \mu \mathrm{M})$ for $8 \mathrm{~h}$. LDH activity was measured in the culture media and expressed as $\mathrm{mU} / \mathrm{ml}$. Data are shown as mean values \pm S.D.; $n=12($ MTT) and $n=3(\mathrm{LDH})$; statistically significant differences: $* \mathrm{P}<0.01$, v.s. BSA-treated control at $250 \mu \mathrm{M}$ fatty acid concentrations; ${ }^{\#} \mathrm{P}<0.01$, v.s. BSAtreated control at $500 \mu \mathrm{M}$ fatty acid concentrations.
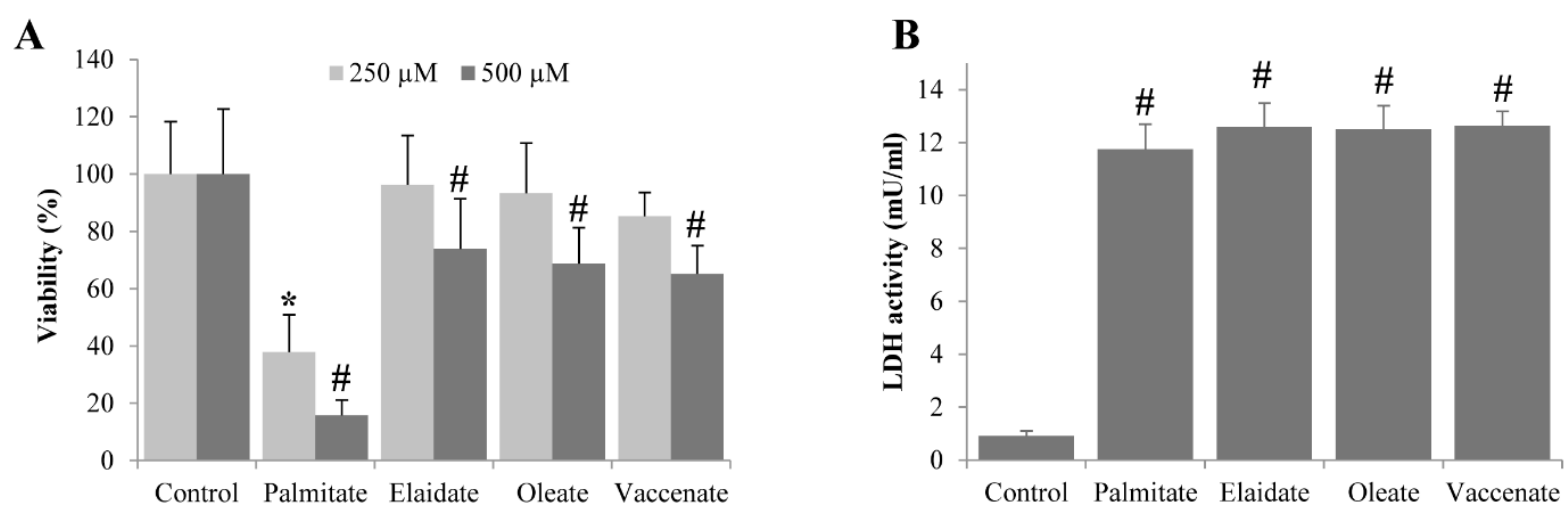
Fig. 2. Apoptosis index. The cells were treated with fatty acids for $8 \mathrm{~h}$. Apoptosis index was calculated as the relative number of apoptotic cells detected by annexin and propidium iodide staining and fluorescence microscopy, and it was expressed as percentage of the total cell number. Typical micrograph images obtained in three independent experiments are presented. Data are shown in the diagram as mean values \pm S.D.; $n=6 ; * \mathrm{P}<0.01$, v.s. BSA-treated control.
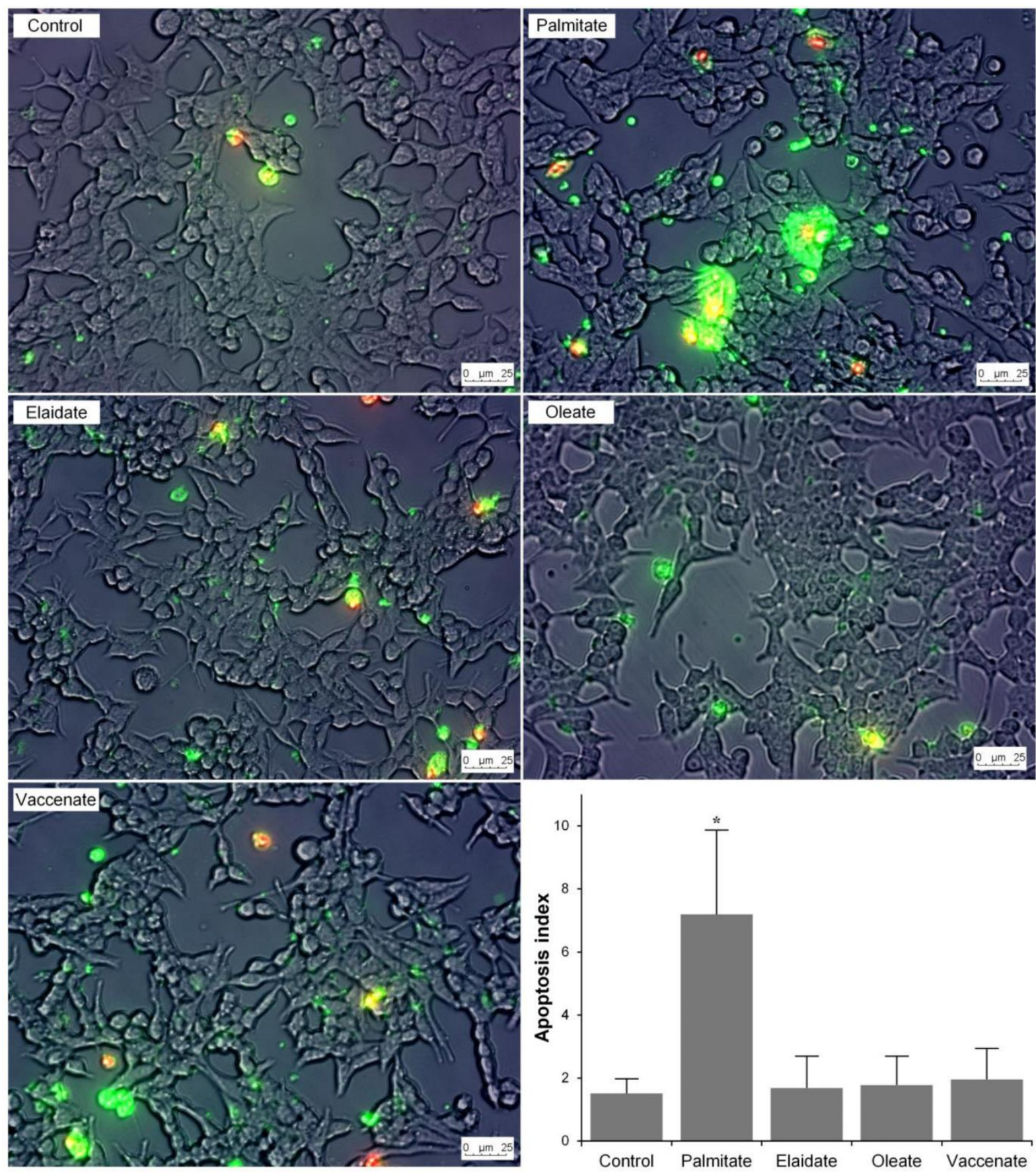
Fig. 3. Apoptosis. The cells were treated with fatty acids for $8 \mathrm{~h}$. Cleaved Caspase-3 (A, lower panel) and Bax (B, lower panel) were detected by western blot in cell lysates. The results were quantified by densitometry, normalized to GAPDH as a constitutive reference protein and are shown as relative band densities in the percentage of palmitate-treated ( $\mathbf{A}$ and $\mathbf{B}$, upper panels). The western blot image shows typical results of three independent experiments with two parallels. Data are shown in the diagrams as mean values \pm S.D.; $n=6$; $* \mathrm{P}<0.01$, v.s. BSAtreated control.
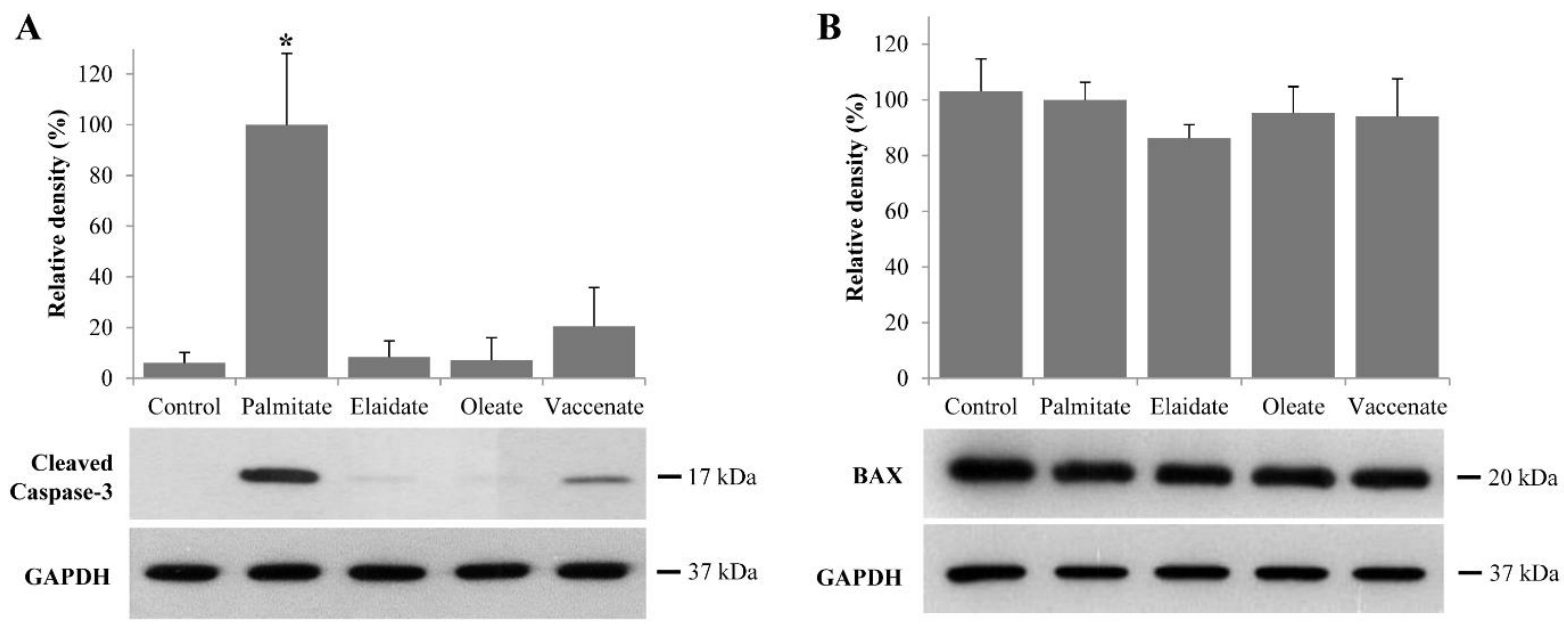
Fig. 4. ER stress markers: splicing of XBP-1 mRNA, phosphorylation of eIF2 $\alpha$ and induction of CHOP. The cells were treated with fatty acids for $8 \mathrm{~h}$. A: Amplified sequences of XBP-1 mRNA were digested with PstI to yield two fragments (153 and 294 bp) of unspliced (uXBP-1) and one (421 bp) of spliced (sXBP-1). The fragments were separated by $2 \%$ agarose gel electrophoresis, and the band densities were quantified by densitometry. The sXBP1/uXBP-1 density ratios were calculated and sXBP-1 fragments were also normalized to GAPDH levels. Typical gel images obtained in one of three independent experiments are presented. B and C: Phosphorylated eIF2 $\alpha(\mathrm{P}-\mathrm{eIF} 2 \alpha)$ and CHOP protein levels were detected by western blot in the cell lysates. The western blot images show typical results of three independent experiments with two parallels. The results were quantified by densitometry, normalized to overall eIF $2 \alpha(\mathbf{B})$ or GAPDH $(\mathbf{C})$ and are presented as relative band densities in the percentage of palmitate-treated. Data are shown as mean values \pm S.D.; $n=6 ; * \mathrm{P}<0.01$, v.s. BSA-treated control.
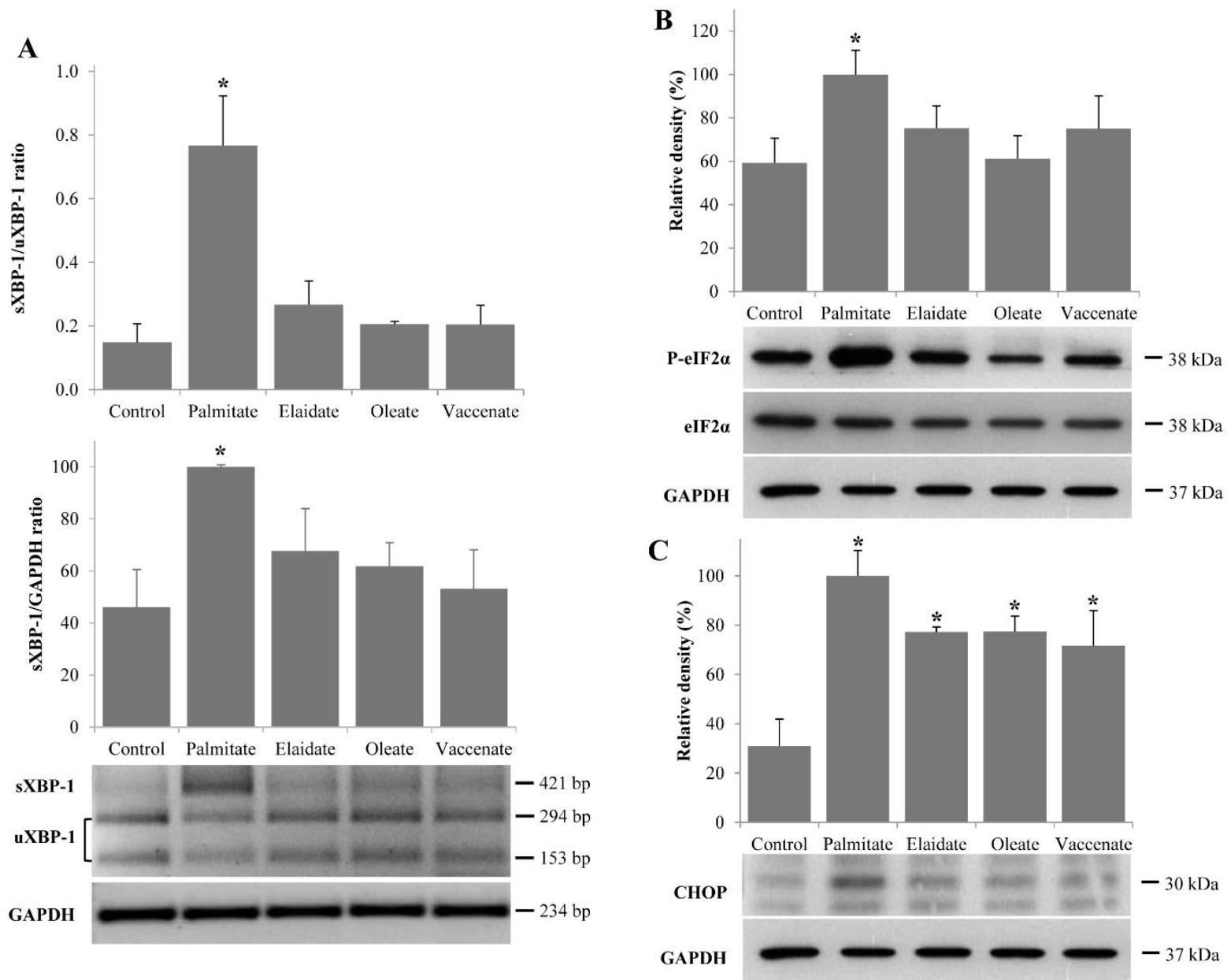
Fig. 5. Expression of the ER chaperons, GRP78/BiP and PDI. The cells were treated with fatty acids for $8 \mathrm{~h}$. GRP78/BiP and PDI protein levels were detected by western blot in the cell lysates. The western blot image shows typical results of three independent experiments with two parallels. The results were quantified by densitometry, normalized to GAPDH as a constitutive reference protein and are presented as relative band densities in the percentage of palmitate-treated. Data are shown as mean values \pm S.D.; $n=6$; $* \mathrm{P}<0.01$, v.s. BSA-treated control.

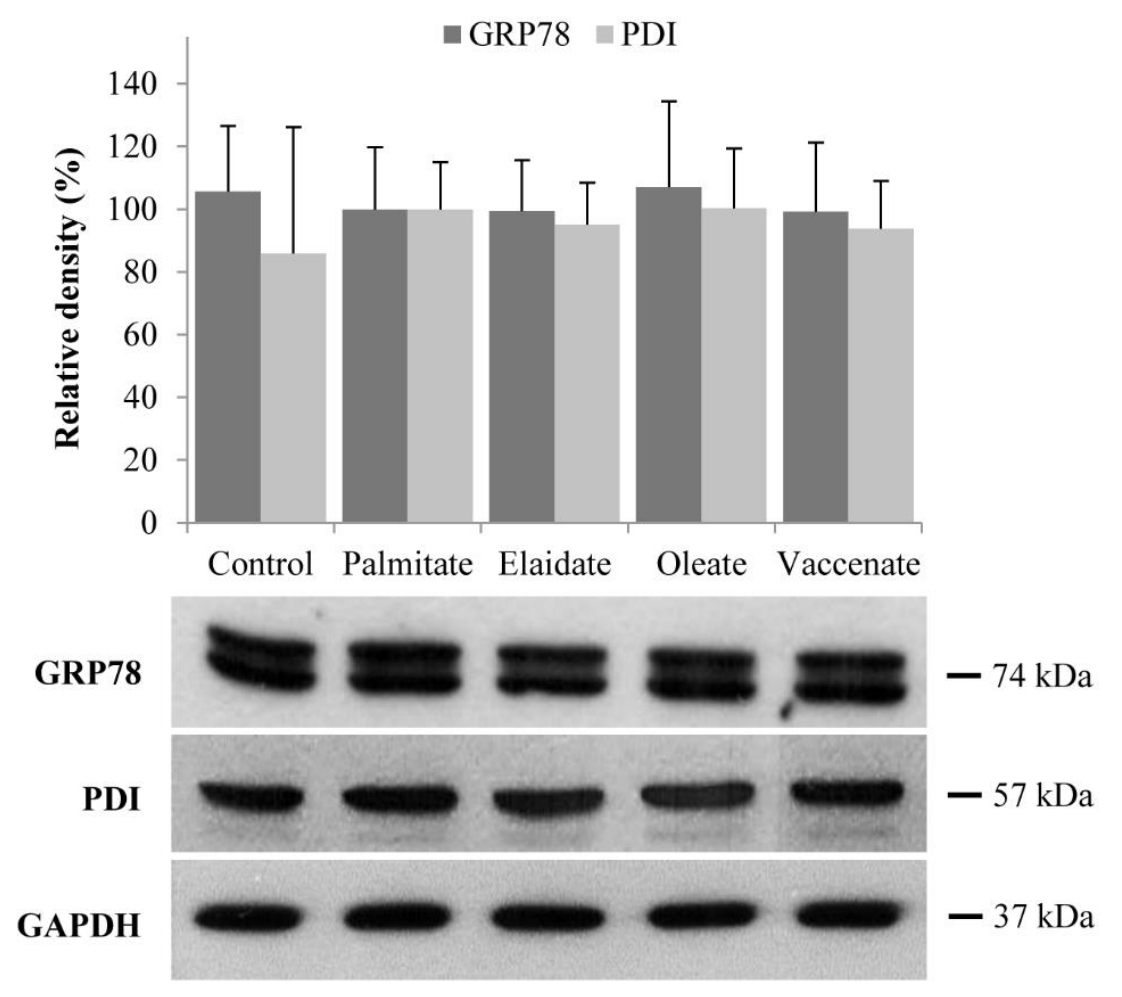


Fig. 6. Phosphorylation of JNK. The cells were treated with fatty acids for $8 \mathrm{~h}$. Total and phosphorylated JNK (two isoforms) were detected by western blot in cell lysates. The western blot image shows typical results of three independent experiments with two parallels. The results were quantified by densitometry, the summed densities of phosphorylated JNK isoforms were normalized to that of GAPDH and they are presented as relative band densities in the percentage of palmitate-treated. Data are shown in the diagram as mean values \pm S.D.; $n=6$; $* \mathrm{P}<0.01$, v.s. BSA-treated control.

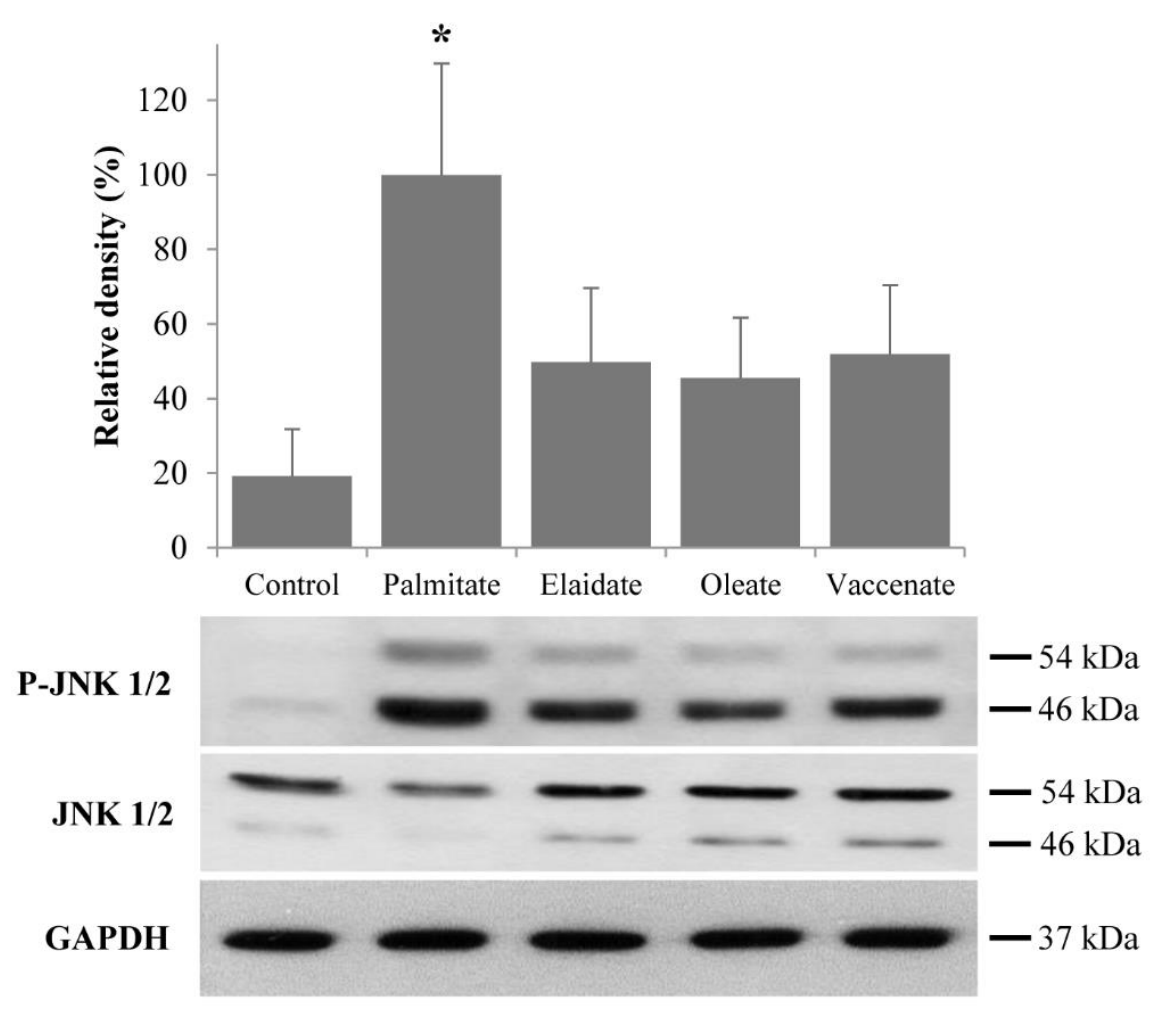


Fig. 7. Changes in the levels of LC3 isoforms. The cells were treated with fatty acids for $8 \mathrm{~h}$. LC3-I and LC3-II isoforms were detected by western blot in the cell lysates. The western blot image presents typical results of three independent experiments with two parallels. The results were quantified by densitometry, normalized to GAPDH and are shown as relative band densities in the percentage of LC3-II in palmitate-treated samples. Data are shown in the diagram as mean values \pm S.D.; $\mathrm{n}=6 ; * \mathrm{P}<0.01$, v.s. BSA-treated control. The calculated ratios of LC3-II and LC3-I densities are inserted in boxes.

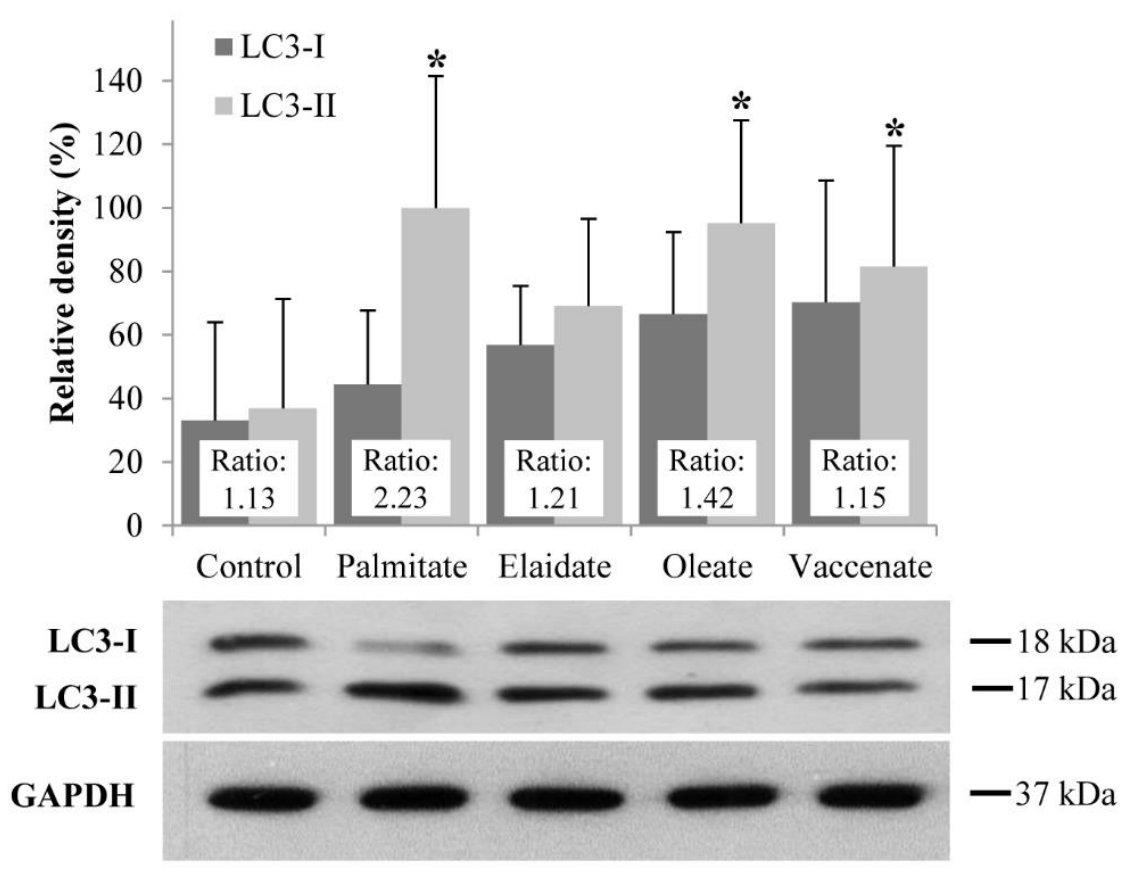


Fig. 8. Ultrastructural changes of the endoplasmic reticulum. The cells were grown on glass cover slips and treated with fatty acids for $8 \mathrm{~h}$. After washing, fixing and embedding, ultrathin sections of the cells were contrasted with uranyl acetate and with Reynold's lead citrate and examined and photographed in a Jeol JEM-1011 electron microscope. Representative ultrastructural images are shown. Bars 500nm; rER, rough endoplasmic reticulum.
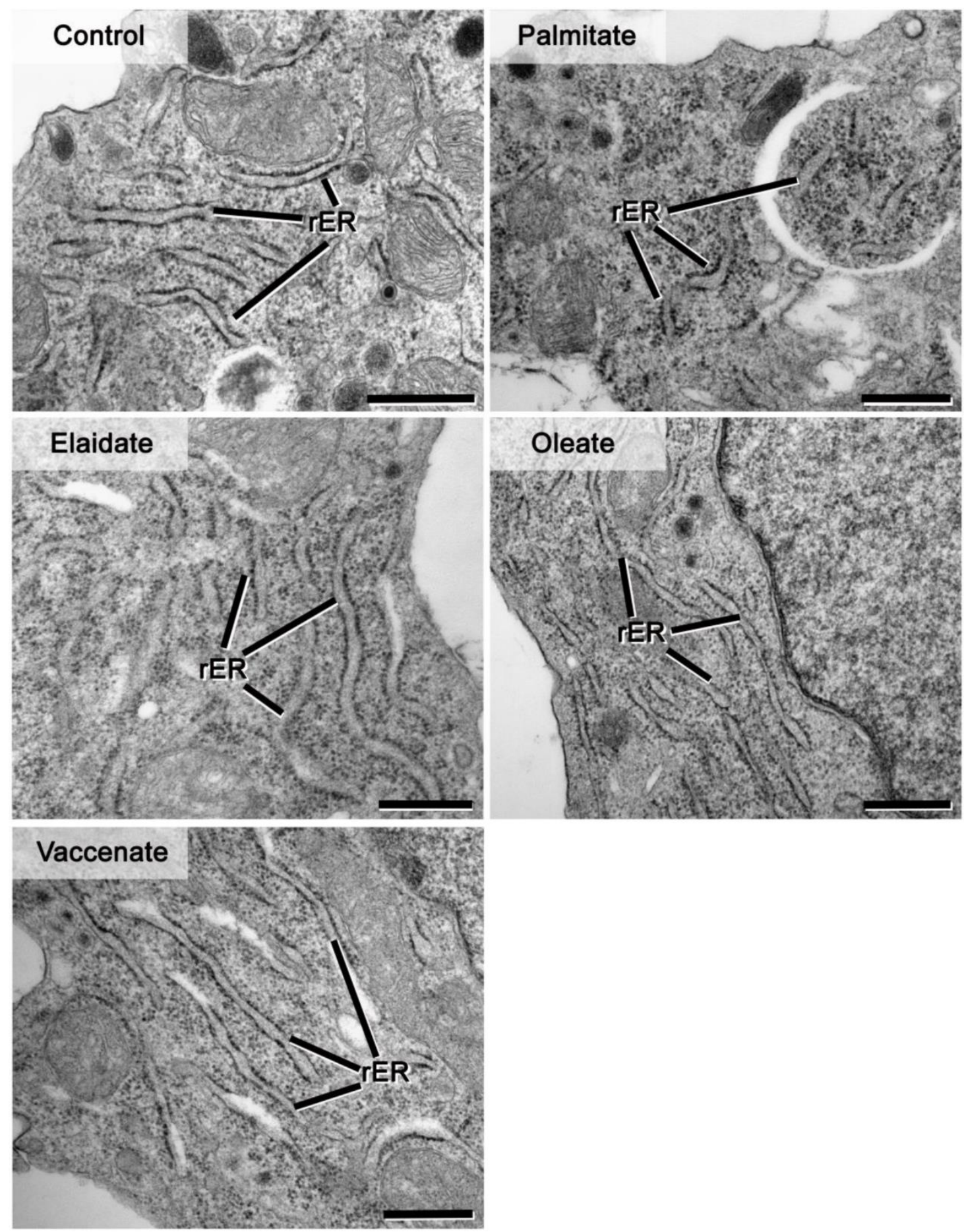
Fig. 9. Autophagic structures detected with electron microscopy. The cells were grown on glass cover slips and treated with fatty acids for $8 \mathrm{~h}$. After washing, fixing and embedding, ultrathin sections of the cells were contrasted with uranyl acetate and with Reynold's lead citrate and examined and photographed in a Jeol JEM-1011 electron microscope. Representative ultrastructural images are shown. The diagram shows the number of autophagic structures per cytoplasmic area in control and fatty acid treated cells. Bars 500nm; Nuc, nucleus; rER, rough endoplasmic reticulum; $\mathrm{Mi}$, mitochondria; $\mathrm{Sg}$, secretory granule; Lys, lysosome; $\mathrm{Ph}$, phagophore, AP, autophagosome; AV, autophagic vacuole.
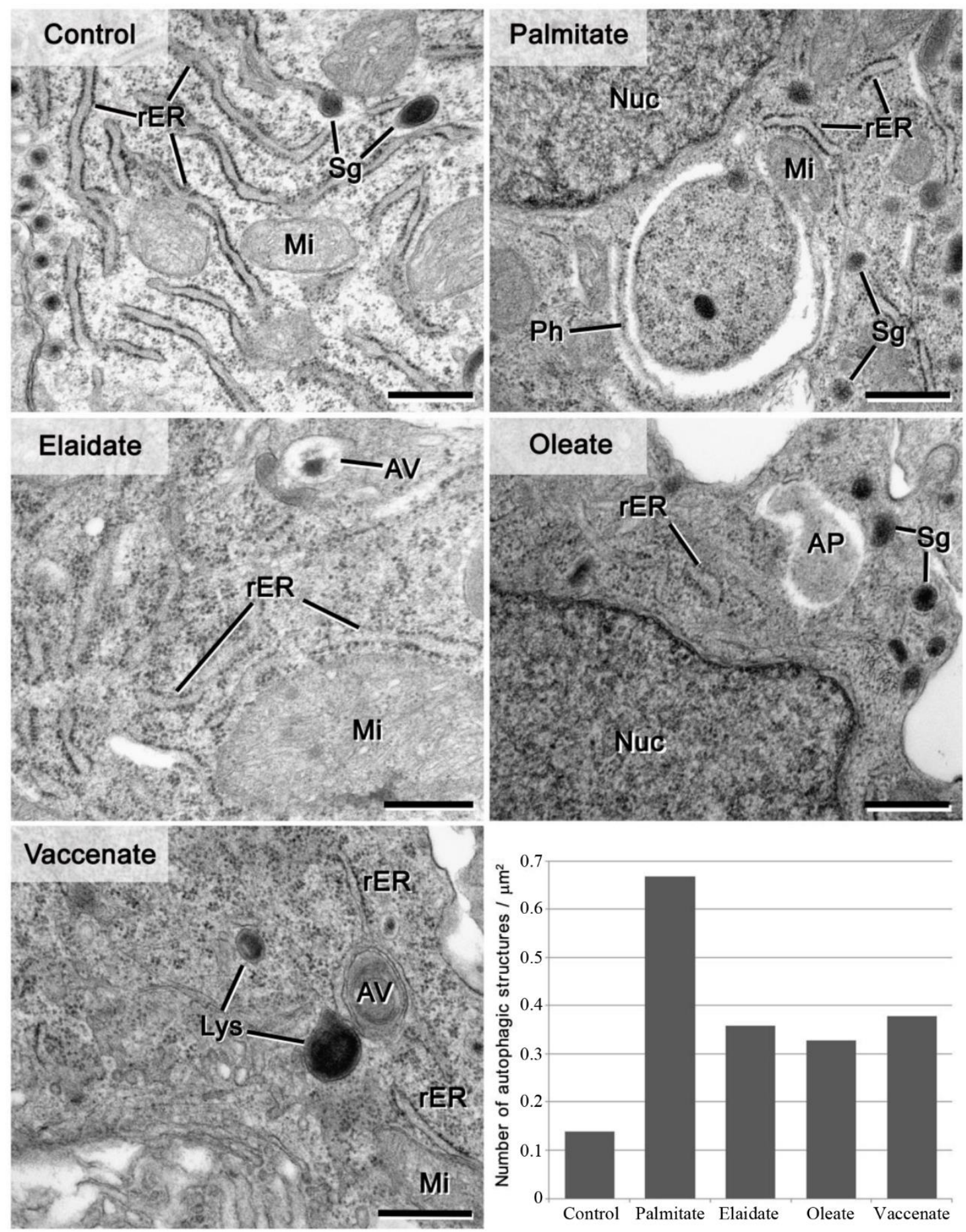
Fig. 10. Changes in the fatty acid profile of the cells. The cells were treated with fatty acids $(250 \mu \mathrm{M})$, samples were withdrawn at 4, 8, 16 and $24 \mathrm{~h}$ times of incubation, and the amount of 10 different saturated and mono-unsaturated fatty acids was measured by GC-FID after saponification and methylation. Data were normalized to the total protein content of the samples, and are shown as mean values \pm S.D.; $n=4$.
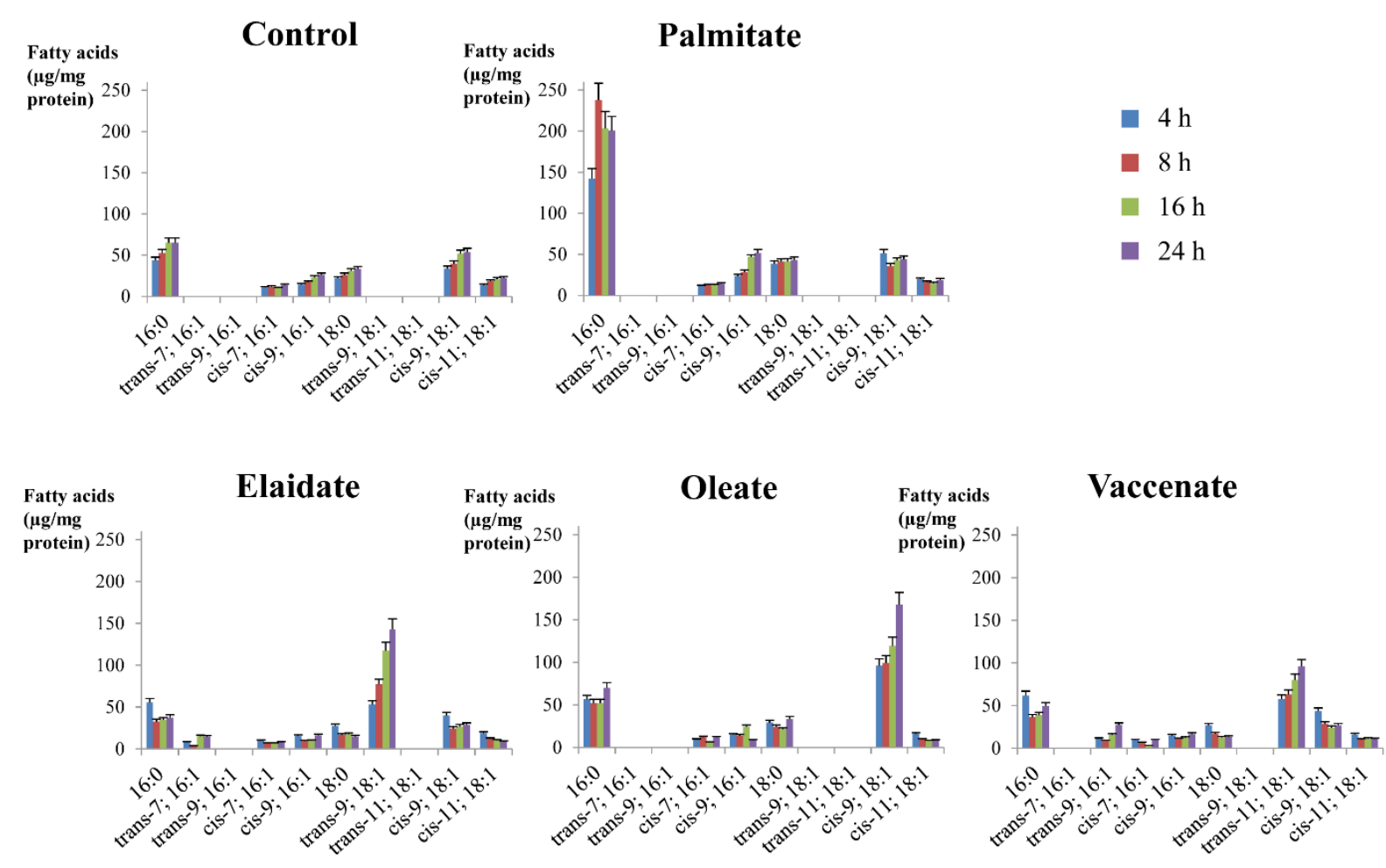
Fig. 11. Accumulation of diglyceride species in fatty acid treated cells. The cells were treated with fatty acids $(250 \mu \mathrm{M})$, samples were withdrawn at $4,8,16$ and $24 \mathrm{~h}$ times of incubation, and the amount of 7 major diglycerides was measured by LC-MS/MS. Data were normalized to the total protein content of the samples, and are shown as mean values, n=4. S.D. was below $10 \%$ of the mean values in all cases.

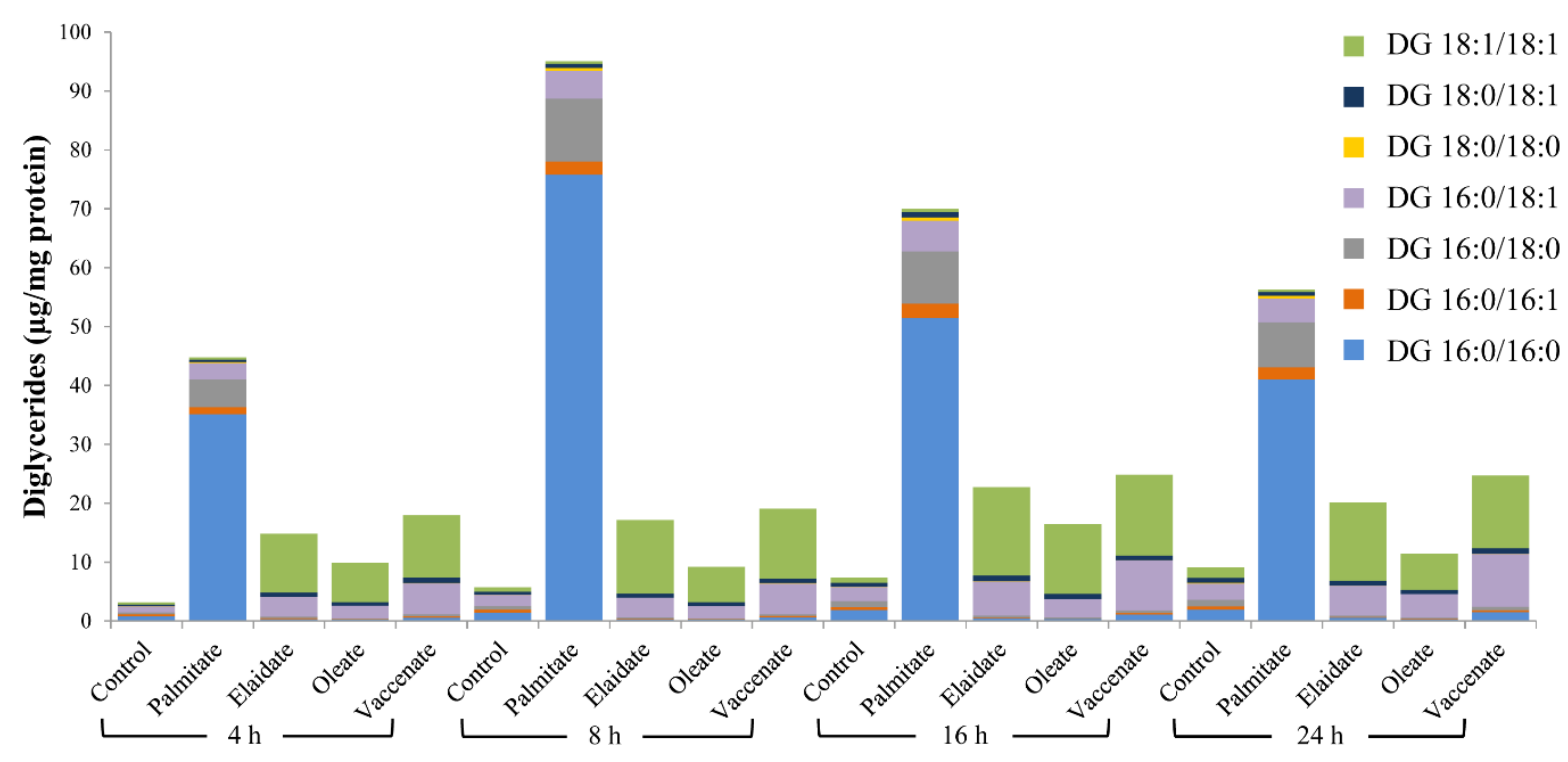


Fig. 12. Incorporation of fatty acids in ceramides. The cells were treated with fatty acids $(250 \mu \mathrm{M})$. The amount of three different ceramide species was measured by LC-MS/MS in the cell samples prepared after $4,8,16$ or 24 hour treatments. The detected ceramides contained either a palmitate $(16: 0)$ or a stearate $(18: 0)$ or a mono-unsaturated fatty acid of 18 carbons (18:1). Data were normalized to the total protein content of the samples, and are shown as mean values, $n=4$. S.D. was below $10 \%$ of the mean values in all cases.

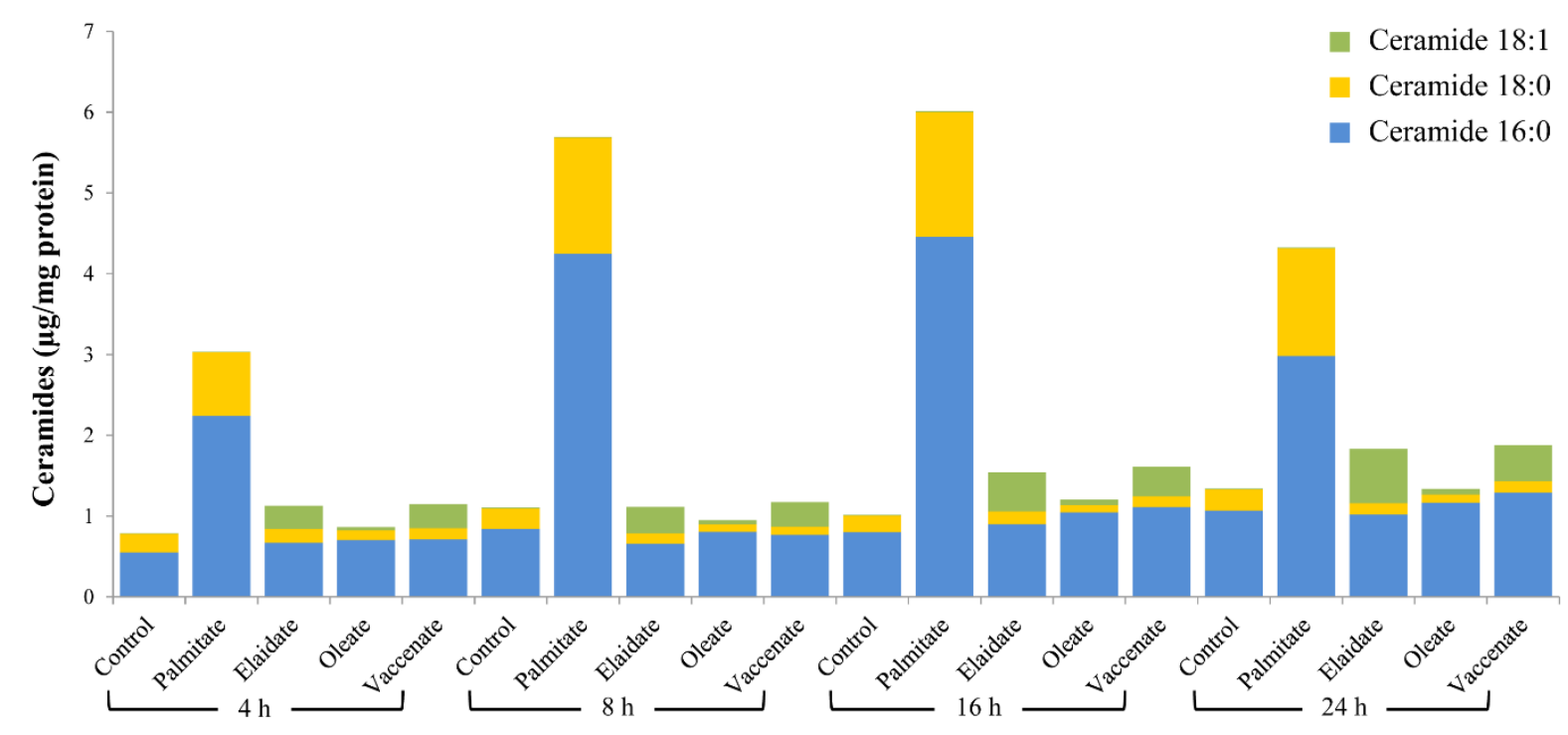

